\title{
Presupposition Projection: the New Debate
}

\author{
Philippe Schlenker \\ Institut Jean-Nicod and New York University
}

\begin{abstract}
A powerful intuition behind much recent research is that a presupposition must be satisfied in its context of evaluation. The relevant notion of context is, in Stalnaker's terminology (Stalnaker 1978), the 'context set', which encodes what the speech act participants take for granted (we will say 'context' for short). But the simplest version of this analysis faces immediate difficulties with complex sentences: John is incompetent and he knows that he is does not require that the speech act participants already take for granted that John is incompetent, since this proposition is asserted, not presupposed. The dynamic approach solves the problem by postulating that the second conjunct is evaluated with respect to a local context, obtained by updating the global one with the content of the first conjunct; this explains why the presupposition of the second conjunct is in this case automatically satisfied. This analysis is captured by the dynamic rule stated in (1): the update of a context $C$ with a conjunction is the successive update of $C$ with each conjunct.
\end{abstract}

(1) $\mathrm{C}[\mathrm{F}$ and $\mathrm{G}]=\mathrm{C}[\mathrm{F}][\mathrm{G}]$

This rule has been interpreted in two ways. For Stalnaker (1974), it is not primitive but rather results from a pragmatic process of information exchange. The analysis was explanatory because it derived the rule from something more basic; but it was not general: it did not easily extend to other connectives and operators. Heim's dynamic semantics (Heim 1983) took the rule to be encoded lexically - which made it possible to extend the theory to other connectives and operators, but at the cost of explanatory depth (Heim 1990, 1992). In recent years, several new theories have sought to get out of this dilemma. We provide a brief survey of some of them, and try to explain how recent experimental data bear on this 'new debate' (important other theories are not discussed for lack of space, Thomason et al. 2006, Unger and van Eijck 2007, as well the exciting new analysis in Chemla 2008a; we also leave a discussion of the DRT approach of van der Sandt 1992 and Geurts 1999 for another occasion).

I wish to thank the following for discussions, critical comments and suggestions: Chris Barkier, Emmanuel Chemla, Danny Fox, Ben George, Benjamin Spector, as well as participants to my seminars at UCLA in the Fall of 2007 and at NYU in the Fall of 2008, and the audience of SALT 2008. Parts of the present discussion appear in Schlenker 2008a, b, 2009, to appear. 


\section{The Problem}

Stalnaker took context update to result from a process of belief revision: as soon as the addressee hears John is incompetent, and unless he objects, he changes his beliefs by accepting this proposition. This was taken to justify the update rule in (1). This approach has great initial force because the assertion of a conjunction can plausibly be equated with the successive assertion of each conjunct. But it doesn't easily extend to other complex sentences, such as those in (2).

(2) a. It didn't rain or it has stopped raining (Presupposition: none)

b. Each of my students has stopped smoking (Presupposition: each of my students used to smoke)

c. None of my students have stopped smoking (Presupposition: each of my students used to smoke)

The point of a disjunction is precisely that one can assert it without being committed to either disjunct; this makes it difficult to see how an assertion-based analysis can be applied to (2)a, despite the fact that there are non-trivial presuppositional facts to account for. In this case, it is the negation of the first disjunct that serves to justify the presupposition of the second one; this fact should presumably follow from a principled account of presupposition projection. When the presuppositional expression is predicative rather than propositional, as is the case in (2)b-c, things are equally difficult: the complex predicate has stopped smoking interacts with the quantifier so as to yield a presupposition that each of my students used to smoke. This fact can be derived by positing that the local context of has stopped smoking is student, which must entail the presupposition used to smoke - which gives the desired result when a generalized notion of entailment (among predicates) is adopted. But the difficulty is that a predicative element just isn't the right kind of object to apply belief update to. More generally, it is unclear how Stalnaker's pragmatic analysis can be applied at the sub-propositional level, as seems to be required here. No detailed account of these cases has been offered along Stalnakerian lines - and the difficulties to be overcome appear to be non-trivial.

Since Stalnaker's pragmatic rationale appeared difficult to extend, Heim 1983 (following in part Karttunen 1974) gave a semantic version of the dynamic analysis, one in which the very meaning of words is dynamic from the start. The update rule in (1) is thus preserved, but it is taken to follow from the lexical meaning of and rather than from a procedure of belief update. The meaning of each word is thus re-analyzed in terms of context change potentials, which are functions from contexts to contexts. It was initially thought that context change potentials could be predicted from truth-conditional properties alone, a claim that Heim later retracted (Heim 1992 fn. 9). For as was noted in the 1980's (e.g. Soames 1989), dynamic semantics is so powerful that it can stipulate in the lexical entry of any operator the way in which it transmits presuppositions. For this reason, the framework is insufficiently explanatory (Heim 1990): any classical operator can be given a variety of dynamic meanings which agree on nonpresuppositional sentences, but make conflicting predictions about 
presuppositional ones; which shows that the dynamic framework fails to predict presupposition projection from truth-conditional content. For instance, dynamic semantics can define a 'deviant' conjunction and ${ }^{*}$ as in (3):

\section{(3) $\mathrm{C}[\mathrm{F}$ and $* \mathrm{G}]=(\mathrm{C}[\mathrm{G}])[\mathrm{F}]$}

In non-presuppositional examples, and $d^{*}$ has the same effect as and: it returns the set of C-worlds that satisfy both $F$ and $G$. But in examples such as John used to smoke and he has stopped, (3) predicts that the sentence should result in a presupposition failure because $\mathrm{C}$ is first updated with the second conjunct before it is updated with the first one. The difficulty is that dynamic semantics has no independent way of ruling out connectives such as and*; taken literally, the framework predicts that such a connective could exist in the world's languages, which does not appear to be correct.

In the recent past, several theories have solved this problem in different and conflicting - ways by meeting the following challenge:

(4) Explanatory Challenge: Find an algorithm that predicts how any operator transmits presuppositions once its syntax and its classical semantics have been specified.

These theories share two features: (a) they take as their input the classical semantic behavior of operators, i.e. their behavior with respect to expressions that contain no presuppositional (or anaphoric) material; (b) they account for presuppositional asymmetries that arise with semantically symmetric operators (such as conjunctions) by explicitly taking into account the linear order in which the arguments appear. But as is illustrated in (5), these theories differ conceptually along four dimensions: 1 . their reliance on local contexts; 2 . their use of trivalence; 3. their semantic or pragmatic nature; 4. the strength of the left-right bias they posit for presupposition projection. They also differ empirically: although they typically agree in the propositional case, they make conflicting predictions with respect to quantified examples.

(5) Explanatory Theories

\begin{tabular}{|c|c|c|c|c|c|}
\hline & $\begin{array}{l}\text { Transparency } \\
\text { Theory } \\
\text { Schlenker } \\
2007,2008\end{array}$ & $\begin{array}{l}\text { Local } \\
\text { Contexts Re- } \\
\text { constructed } \\
\text { Schlenker } \\
2009\end{array}$ & $\begin{array}{l}\text { Constrained } \\
\text { Dynamic } \\
\text { Semantics } \\
\text { Rothschild } \\
\text { 2008a, b, } \\
\text { LaCasse } 2008\end{array}$ & $\begin{array}{l}\text { Trivalent } \\
\text { Theories } \\
\text { George } \\
2008 a, b \text {, } \\
\text { Fox } 2008\end{array}$ & $\begin{array}{l}\text { Similarity: } \\
\text { Presuppositions } \\
\text { qua implicatures } \\
\text { Chemla } 2008 b\end{array}$ \\
\hline $\begin{array}{l}\text { 1. Local } \\
\text { Contexts? }\end{array}$ & No & Yes & Yes & No & No \\
\hline 2. Trivalence? & No & No & Yes & Yes & No \\
\hline 3. Pragmatic? & Yes & Yes & No & Yes/No & Yes \\
\hline $\begin{array}{l}\text { 4. Incremental } \\
\text { /Symmetric? }\end{array}$ & Yes & Yes & Yes/No & Yes/No & Yes \\
\hline
\end{tabular}

Each line of the table starts with a question: (i) Does the theory posit local contexts? (ii) Does it rely on 
trivalence? (iii) Is its account of projection pragmatic? (iv) Does it take left-right asymmetries to be a bias that can be overridden $(=$ Yes $)$, or to be a core property of presupposition projection $(=$ No) ? Each column provides an answer; Yes/No indicates that different versions of a given theory provide different answers.

\section{New Experimental Data}

The empirical side of the debate has been enriched, and constrained, by new experimental data due to Emmanuel Chemla (2007, to appear). Using an inferential paradigm (e.g. does sentence $S$ 'suggest' inference I ?), Chemla confirmed the characterization of presuppositions in simple cases; for instance, presuppositions do indeed project out the scope of negation, as everyone thought. Similarly, a yes-no question inherits the presupposition of the corresponding assertion. But in other cases Chemla established data that were debated, or not discussed in the literature. Thus presupposition triggers that appear in the scope of quantifiers were taken by Heimian accounts to give rise to universal inferences: No student takes care of his computer was thought to presuppose that every student has a computer. By contrast, Beaver $(1994,2001)$ took the presupposition to be existential, and to lead just to an inference that at least one of these ten students has a computer. As for presupposition triggers that appear in the restrictor of a quantifier, the data had barely been discussed in the literature, but Heimian accounts predicted a universal presupposition (No student who takes care of his computer will have problems was taken to presuppose that every student has a computer).

Chemla applied his inferential paradigm to French, and took great care to use highly explicit restrictors (e.g. none of these ten students, each of these ten students) so as to make it unlikely that an additional domain restriction is assumed, which would make the results difficult to interpret. The triggers he used were factive verbs, definite descriptions, and change of state verbs (on the other hand he did not use 'anaphoric' triggers such as too and again, a point to which we return at the end of this paper). He relied on two experimental methodologies: one was to ask subjects, in a binary task, whether they did or did not obtain a particular inference; another one was to ask them to evaluate the strength of the inference. Both methodologies established three major results.

1. When a trigger appeared in a nuclear scope, the inference obtained depends on the particular quantifier which is used. Each of these ten students takes care of his computer and None of these ten students takes care of his computer both led to a strong inference that each of these ten students has a computer; but with other quantifiers (at least five, exactly five, less than five), subjects were at chance with respect to the universal inference.

2. When a trigger appeared in the restrictor of a quantifier, patterns of universal projection were not found, or only in very weak form.

These results are summarized in (6), which plots the robustness of universal inferences obtained depending on the quantifier and on the position (restrictor vs. 
nuclear scope.

(6) Chemla's experimental results (from Chemla, to appear)

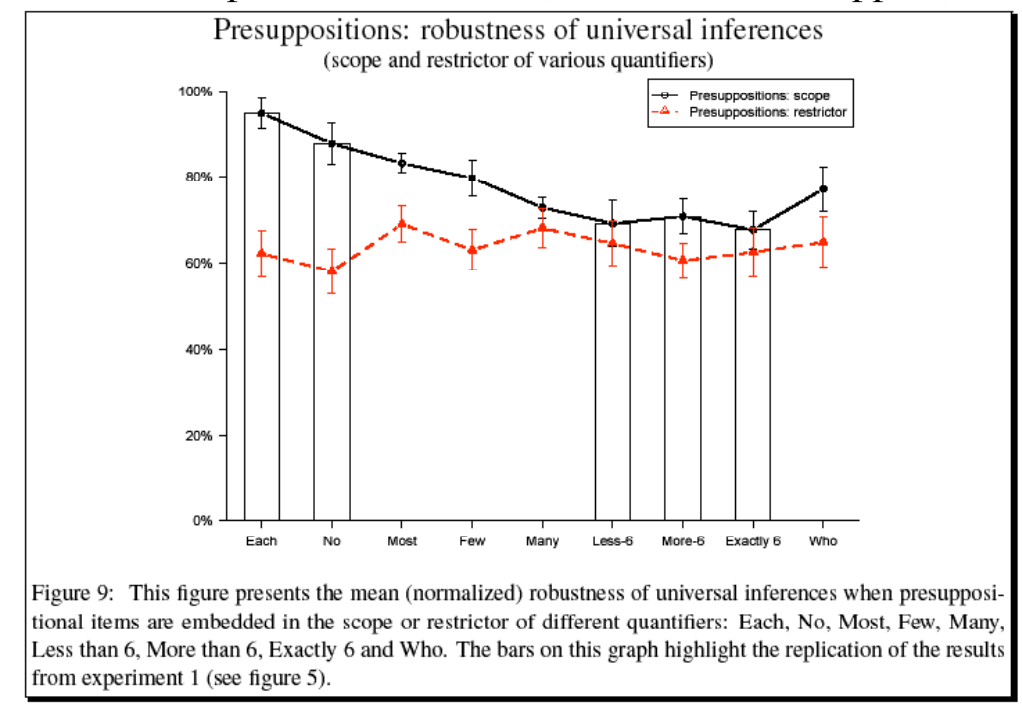

Both results are a clear challenge to Heim's theory.

3. Comparing the trials in which a subject did compute a presupposition to those in which s/he failed to do so, Chemla showed that reaction times were slower in the latter case than in the former. In other words, failing to compute a presupposition appears to take time. This is the opposite of the result that has been found in the literature on scalar implicatures: subjects take less time when they fail to compute an implicature than when they do compute it. Such a result is consistent with the view that implicatures require a pragmatic reasoning which takes some time to compute (as opposed to entailments, which follow from the semantic meaning of sentences). On the other hand, Chemla's result about presuppositions is consistent with the commonly accepted view that presuppositions follow from the meaning of a sentence, and that a costly process 'local accommodation' - is necessary to 'get rid' of them. The new theories should eventually account for these data too.

We will briefly sketch the debate between four of the new theories: the Transparency theory (Schlenker, 2007, 2008a) and the reconstruction of local contexts developed in Schlenker (to appear) - which are conceptually very different but technically close; the trivalent theories of presupposition recently revived by George (2008a, b) and Fox (2008); and the constrained versions of dynamic semantics explored by Rothschild (2008a, b) and LaCasse (2008). (Chemla's Similarity theory (2008), which is one of the most interesting developments in this domain, is harder to compare with the other theories and is not discussed in this survey).

\section{The Transparency Theory}




\subsection{Principles}

The Transparency theory purports to do without any notion of local context, and to explicate presupposition projection in purely pragmatic terms, on the basis of two Gricean principles of manner. We start from a sentence $S$ and a specification of its classical semantics, and of the presupposition triggers that appear in it. We adopt the convention of writing as $\underline{d} d^{\prime}$ ' a propositional or predicative expression that has a presupposition $d$ (which we underline) and an assertive component $d$ '. The analysis goes as follows.

-A presupposition is viewed as a distinguished entailment, one that 'wants' to be articulated as a separate conjunct. So the semantics treats $\underline{d} d$ ' as if it were just the conjunction of $d$ and $d$. But the pragmatics specifies that in any syntactic environment, one should if possible say ... ( $d$ and $\left.\underline{d} d d^{\prime}\right) \ldots$ rather than just ... $\underline{d} d^{\prime} \ldots$. All things being equal, then, one should say It is raining and John knows it rather than John knows that it is raining. The constraint that requires that presuppositions be articulated separately is called Be Articulate; it can be seen as a Gricean maxim of manner, since it imposes a condition on the way in which certain meanings should be expressed ${ }^{1}$.

(7) Be Articulate

Say $a$ ( $d$ and $\left.\underline{d} d^{\prime}\right) b$ rather than $a \underline{d} d^{\prime} b$.

-A second principle of manner, Be Brief, limits the effects of Be Articulate. The intuition is that in any syntactic environment $a \_b$, one should not say $a$ ( $d$ and blah) $b$ in case the words $d$ and are certain to be eliminable without truthconditional loss.

The Transparency theory accounts for the presuppositional asymmetry obtained with semantically symmetric connectives (such as and) by taking $B e$ Brief to come with a linear bias: $d$ and is considered idle in case no matter what follows, these words are certain to be eliminable given what is already assumed in the conversation. For instance, if it is already assumed that John is in Paris, it will be idle to start any sentence with John is in Paris and ... . Similarly, even if the context does not initially entail that John is in Paris, it will be idle to start a sentence with If John is staying near the Louvre, he is in Paris and ...: here too, the words in bold are certain to be eliminable without truth-conditional loss. Calling a 'good final' for a string $s$ a string $s$ ' that guarantees that $s s$ ' is a well-

\footnotetext{
1 As Rothschild (2008b) points out, the 'pragmatic prohibition' against 'using one short construction to express two independent meanings' was explicitly discussed by Grice. Specifically, Grice (1981) proposed to add a new maxim of manner to account for presuppositions; its statement was very close to Be Articulate: 'if your assertions are complex and conjunctive, and you are asserting a number of things at the same time, then it would be natural, on the assumption that any one of them might be challengeable, to set them out separately and so make it easy for anyone who wanted to challenge them to do so' (Grice 1981). See also Stalnaker 1974 for a related idea.
} 
formed sentence, we are led to the following statement of Be Brief - which we call 'incremental' because it incorporates a left-right bias (information that comes before a presupposition trigger is taken into account, information that comes after isn't).

(8) Be Brief - Incremental Version

Let $\mathrm{C}$ be a context set, and let $d$ be an occurrence of an expression whose type 'ends in t' in a sentence $a$ ( $d$ and $d$ ') $b$.

$d$ violates Be Brief just in case for any expression $g$ of the same type as $d$, for any good final $b^{\prime}, \quad \mathrm{Cl}=\mathrm{a}$ (d and $\mathrm{g}$ ) b' $\Leftrightarrow \mathrm{a} \mathrm{g} \mathrm{b}$.

Terminology: when $d$ violates this principle, we say that it is (incrementally) transparent.

With these principles in place, a theory of presupposition projection can be developed by positing that Be Brief cannot be violated, while Be Articulate can be. This may be encoded by postulating (for instance in an optimality-theoretic framework) that Be Brief is more highly ranked than Be Articulate:

(9) Be Brief $>>$ Be Articulate

Together, these principles predict that in any syntactic environment a presupposition trigger ... $\underline{d} d^{\prime}$ '... must be expressed as ...(d and $\left.\underline{d} d^{\prime}\right) \ldots$, unless $d$ is in violation of Be Brief (which happens if case $d$ is incrementally transparent). We call this the 'principle of Transparency' (or simply 'Transparency'); and to indicate that $\underline{d} d$ ' is acceptable in the string $a \underline{d} d$ ' $b$ uttered in a context set $\mathrm{C}$, we write $\operatorname{Transp}\left(\mathrm{C}, \underline{\mathrm{dd}}\right.$ ', $\left.\mathrm{a} \_\mathrm{b}\right)$, with the following definition:

(10) Transp(C, dd', a_b) iff for every expression $g$ of the same type as $d$, for every good final $b^{\prime}, \mathrm{C}=\mathrm{a}(\mathrm{d}$ and $\mathrm{g}) \mathrm{b}^{\prime} \Leftrightarrow \mathrm{a} \mathrm{g} \mathrm{b}$ '

Finally, we can say that formula $F$ uttered in a context $\mathrm{C}$ is acceptable according to the Transparency theory just in case every occurrence of any presupposition trigger $\underline{d} d$ ' is acceptable:

(11) Transp (C, F) iff for every expression of the form $\underline{d} d^{\prime}$, for all strings $a, b$, if $F$ $=a \underline{d} d^{\prime} b$, then Transp $\left(\mathrm{C}, \underline{\mathrm{dd}}\right.$ ', $\left.\mathrm{a} \_\mathrm{b}\right)$

\subsection{Fragment}

To illustrate the analysis, we apply it to a highly simplified language which is structurally disambiguated by the use of parentheses. We mostly restrict attention to simple sentences of the form $p$, (not $F)$, ( $F$ and $G),(F$ or $G)$, (if $F$. $G$ ), (No P. $R)$, (Every $P . P$ ), and similarly for other quantifiers. The syntax of our fragment is defined in (12); it includes generalized quantifiers, which take two predicative arguments. As before, presupposition triggers are underlined; for instance, stop 
smoking could be represented as a predicate $\underline{P}_{i} P_{k}$ with $P_{i}=$ used to smoke and $P_{k}$ $=$ doesn't smoke (we come back to syntactic issues in Section 8).

(12) Syntax

a. Predicates: $\mathrm{P}::=\mathrm{P}_{\mathrm{i}} \mid \underline{\mathrm{P}}_{\mathrm{i}} \mathrm{P}_{\mathrm{k}}^{2}$

b. Propositions: $\mathrm{p}::=\mathrm{p}_{\mathrm{i}} \mid \mathrm{p}_{\mathrm{i}} \mathrm{p}_{\mathrm{k}}$

c. Formulas $\mathrm{F}::=\mathrm{p} \mid($ not F $) \mid(\mathrm{F}$ and F $) \mid(\mathrm{F}$ or F $) \mid($ if F. F $) \mid($ Every P . P $) \mid$

(No P . P) I (Most P . P) I (Less than 5 P. P) I etc.

By contrast with Heim's dynamic framework, our semantics is bivalent and classical. It is standard, except that expressions of the form $\underline{P}_{i} P_{k}$ and $\underline{p}_{i} p_{k}$ are interpreted as the (predicative or propositional) conjunction of their two components. Since this semantics will be used in several of the analyses under discussion, it is worth spelling out in detail. For notational simplicity, we write as $\mathbf{E}$ the semantic value of an expression $E$; and we write as $\mathbf{E}^{\mathrm{w}}$ the value of $E$ evaluated in a world w.

(13) Semantics

We take as given a domain $\mathrm{D}$ of individuals and a domain $\mathrm{W}$ of possible worlds.

a. The initial valuation I assigns to each elementary predicate $P_{i}$ a value $\mathbf{P}_{\mathbf{i}}{ }^{\text {w }}$

$\subseteq \mathrm{W}$ and to each elementary proposition $p_{i}$ a value $\mathbf{p}_{\mathbf{i}}{ }^{\mathrm{W}} \in\{0,1\}$.

$\mathrm{b}$. $\mathrm{I}$ is then extended to the entire language. For any world $\mathrm{W}$ of $\mathrm{W}$,

$\left(\mathbf{p}_{i} \mathbf{p}_{\mathbf{k}}\right)^{\mathrm{w}}=1$ iff $\mathbf{p}_{\mathbf{i}}{ }^{\mathrm{w}}=\mathbf{p}_{\mathbf{k}}{ }^{\mathrm{w}}=1 ;\left(\underline{\mathbf{P}}_{\mathbf{i}} \mathbf{P}_{\mathbf{k}}\right)^{\mathrm{w}}=\mathbf{P}_{\mathbf{i}}{ }^{\mathrm{w}} \cap \mathbf{P}_{\mathbf{k}}{ }^{\mathrm{w}} ; \quad(\boldsymbol{n o t} \mathbf{F})^{\mathrm{w}}=1$ iff $\mathbf{F}^{\mathrm{w}}=0 ;(\mathbf{F}$ and $\left.\mathbf{F}^{\prime}\right)^{\mathrm{w}}=1$ iff $\mathbf{F}^{\mathrm{w}}=\mathbf{F}^{\text {, }}{ }^{\mathrm{w}}=1$; $\left(\mathbf{F} \text { or } \mathbf{F}^{\prime}\right)^{\mathrm{w}}=1$ iff $\mathbf{F}^{\mathrm{w}}=1$ or $\mathbf{F}^{{ }^{\mathrm{w}}}=1$; (if $\mathbf{F}$.

$\left.\mathbf{F}^{\prime}\right)^{\mathrm{w}}=1$ iff $\mathbf{F}^{\mathrm{w}}=0$ or $\mathbf{F}^{\boldsymbol{g}^{\mathrm{w}}}=1$; $\left(\text { Every } \mathbf{P} . \mathbf{P}^{\prime}\right)^{\mathrm{w}}=1$ iff every object $\mathrm{d} \in \mathrm{D}$ such that $\mathrm{d} \in \mathbf{P}^{\mathrm{w}}$ satisfies $\mathrm{d} \in \mathbf{P}^{\mathrm{w}} ;\left(\mathbf{N o} \mathbf{P} \text {. } \mathbf{P}^{\prime}\right)^{\mathrm{w}}=1$ iff no object $\mathrm{d} \in \mathrm{D}$ such that $\mathrm{d}$ $\in \mathbf{P}^{\mathrm{w}}$ satisfies $\mathrm{d} \in \mathbf{P}^{\mathrm{w}}$; $\left(\text { Most } \mathbf{P} \text {. } \mathbf{P}^{\prime}\right)^{\mathrm{w}}=1$ iff more than half of the objects $\mathrm{d}$ $\in \mathrm{D}$ such that $\mathrm{d} \in \mathbf{P}^{\mathrm{w}}$ satisfy $\mathrm{d} \in \mathbf{P}^{\prime} ;\left(\text { Exactly } 5 \mathbf{P} \text {. } \mathbf{P}^{\prime}\right)^{\mathrm{w}}=1$ iff exactly 5 of the objects $d \in D$ such that $d \in \mathbf{P}^{\mathrm{w}}$ satisfy $d \in \mathbf{P}^{\prime}$; etc.

Notation: we will often write $w /=F$ if the formula $F$ is true in the world w; and we will write $C I=F$ if the formula $F$ is true in each of the worlds in the context set $\mathrm{C}$. If $\mathrm{Cl}=\mathrm{F} \Leftrightarrow \mathrm{G}$, we say that $F$ and $G$ are contextually equivalent.

\subsection{Examples}

With this background in mind, we consider four examples, which we treat in some detail because they illustrate techniques that will also be useful for the other accounts we will consider. In each case, we (a) specify the principle of Transparency, (b) state the result to be derived, and (c) prove it. In general, the

${ }^{2}$ To apply Be Articulate, we informally enrich (12)a with a rule of predicate conjunction [P ::= $\left(\mathrm{P}_{\mathrm{i}}\right.$ and $\left.\mathrm{P}_{\mathrm{k}}\right)$ ], with the natural interpretation. The same extension is assumed throughout our discussion of trivalence in Section 5. 
only non-trivial part consists in showing that if the principle of Transparency is satisfied, then the desired result holds. The fact that the principle is stated as a universal statement ("for every expression $g$ of the same type as $d$, for every good final $b ', \ldots$ ") is crucial: to show that the desired result holds, it is enough to find some expression $g$ and some good final $b$ ' that enforce the desired result - a technique which is used in each of the following examples.

Let us first consider the case in which a presupposition trigger appears in the first part of a conjunction ( $q q^{\prime}$ and p), for instance the sentence John knows that he is incompetent, and he is depressed. It is traditionally thought that this sentences presupposes $q$ - i.e. John is incompetent. Transparency predicts that the sentence is acceptable just case an attempt to be articulate and thus to say ( $q$ and $\left.q q^{\prime}\right)$ and $p$ ) runs afoul of Be Brief because for any proposition $g$, for any good final $b^{\prime},\left((q\right.$ and $g) b^{\prime}$ is contextually equivalent to $(g b$ ' (we use square brackets for legibility, but they are not part of the object language).

\section{(14) (qq' and p) presupposes $p$}

a. Transparency requires that for each clause $g$ and for each good final $b$ ', $\mathrm{Cl}=\left[\left((\mathrm{q}\right.\right.$ and $\left.\mathrm{g}) \mathrm{b}^{\prime}\right] \Leftrightarrow\left[\left(\mathrm{g} \mathrm{b}^{\prime}\right]\right.$

b. Claim: Transparency is satisfied $\Leftrightarrow \mathrm{Cl}=\mathrm{q}$

c. Proof

$\Rightarrow$ : Suppose that Transparency is satisfied. In particular, taking $g$ to be a tautology $T$ and $b$ ' to be the string and and $T)$, we have:

$\mathrm{Cl}=[((\mathrm{q}$ and $\mathrm{T})$ and $\mathrm{T})] \Leftrightarrow[(\mathrm{T}$ and $\mathrm{T})]$

It immediately follows that $\mathrm{Cl}=\mathrm{q}$.

$\Leftarrow$ : Suppose that $\mathrm{Cl}=\mathrm{q}$. Then for any propositional $g, \mathrm{Cl}=(\mathrm{q}$ and $\mathrm{g}) \Leftrightarrow \mathrm{g}$. So $((q$ and $g) b$ ' is obtained from $(g b$ ' by replacing the constituent $g$ with a constituent - namely ( $q$ and $g$ ) - which has the same truth conditions relative to $\mathrm{C}$. Since our fragment is extensional, the two formulas are equivalent.

As stated, the principle of Transparency only considers the part of a sentence that precedes the presupposition trigger; it is thus immediate that the same predictions are made for $\left(q q^{\prime}\right.$ or $p$ ) as for ( $q q^{\prime}$ and $p$ ) - which might explain why a presupposition that John is incompetent is obtained in the sentence John knows that he is incompetent, or he is depressed (we reconsider this point in Section 7, where non-incremental theories of presupposition projection are discussed).

Let us turn to the case in which the presupposition trigger appears in the second part of a conjunction. A standard result of Stalnaker's and Heim's analyses is that ( $p$ and $q q$ ') presupposes (if $p$. q). For instance, John is 64 years old and he knows that he cannot be hired is predicted to presuppose that if John is 64 years old, he cannot be hired. In this case, the incremental nature of the analysis will play no role: when one has seen ( $p$ and ( $d$ and $g$ ), where $g$ is a constituent, one can tell that the only way to complete this string to obtain a wellformed formula is to add to it the right parenthesis, yielding ( $p$ and ( $d$ and $g$ )); for 
( $d$ and $g$ ) is a constituent, and the only way it could have been put next to the first and is by an application of the syntactic rule for conjunctions, which automatically adds the right parenthesis too. The result is that quantification over good finals plays no role in this example - and the point generalizes to all other cases in which the presupposition trigger appears at the end of the sentence. This makes it straightforward to derive the desired result.

(15) ( $p$ and $q q^{\prime}$ ) presupposes (if $p$.q)

a. Transparency requires that for each propositional $g$ and for each good final $b^{\prime}, \mathrm{Cl}=\left[\left(\mathrm{p}\right.\right.$ and $(\mathrm{q}$ and $\left.\mathrm{g}) \mathrm{b}^{\prime}\right] \Leftrightarrow\left[\left(\mathrm{p}\right.\right.$ and $\left.\mathrm{g} \mathrm{b} \mathrm{b}^{\prime}\right]$

b. Claim: Transparency is satisfied $\Leftrightarrow \mathrm{Cl}=$ (if $\mathrm{p} . \mathrm{q}$ )

c. Proof

$\Rightarrow$ : Suppose that Transparency is satisfied. In particular, taking $b^{\prime}$ to be the right parenthesis ) and $g$ to be a tautology $T$, we have:

$\mathrm{Cl}=(\mathrm{p}$ and $(\mathrm{q}$ and $\mathrm{T})) \Leftrightarrow(\mathrm{p}$ and $\mathrm{T})$, hence $\mathrm{Cl}=(\mathrm{p}$ and $\mathrm{q}) \Leftrightarrow \mathrm{p}$,

and in particular

$\mathrm{Cl}=\mathrm{p} \Rightarrow \mathrm{q}$. But since we treat conditionals as material implications, this is just to say that $\mathrm{Cl}=$ (if $\mathrm{p}$. q).

$\Leftarrow$ : Suppose that $\mathrm{Cl}=\mathrm{p} \Rightarrow \mathrm{q}$. Then for each clause $g, \mathrm{Cl}=(\mathrm{p}$ and $(\mathrm{q}$ and $\mathrm{g}))$

$\Leftrightarrow(\mathrm{p}$ and $\mathrm{g})$. Since the only value of $b^{\prime}$ that makes it a good final is $\left.b^{\prime}=\right)$, it also follows that for every good final $b^{\prime}$,

$\mathrm{C} I=\left[\left(\mathrm{p}\right.\right.$ and $(\mathrm{q}$ and $\left.\mathrm{g}) \mathrm{b}^{\prime}\right] \Leftrightarrow\left[(\mathrm{p}\right.$ and $\left.\mathrm{g}) \mathrm{b}^{\prime}\right]$

Let us turn to conditionals. It can be shown that the case of (if $p p^{\prime} . q$ ) is similar to $\left(p p^{\prime}\right.$ and $\left.q\right)$ : the entire sentence is predicted to presuppose $p$. More interesting is the case in which the presupposition trigger is in the consequent of the conditional. We do derive Heim's result that (if $p . q q^{\prime}$ ) presupposes (if $p$. q); thus we predict a presupposition that If John is 64 years old, he cannot be hired for the sentence If John is 64 years old, he knows that he cannot be hired. The derivation of this result is given in (16); here too we use the fact that the only good final is the right parenthesis.

(16) (if $\left.p \cdot q q^{\prime}\right)$ presupposes (if $\left.p . q\right)$

a. Transparency requires that for each clause $g$ and each good final $b$,

$\mathrm{C} I=\left[\right.$ (if $\mathrm{p}$. (q and g) b'] $\Leftrightarrow\left[\right.$ (if $\left.\mathrm{p} \cdot \mathrm{g} \mathrm{b}^{\prime}\right]$

b. Claim: Transparency is satisfied $\Leftrightarrow \mathrm{Cl}=\mathrm{p} \Rightarrow \mathrm{q}$

c. Proof

$\Rightarrow$ : Suppose that Transparency is satisfied. In particular, taking $b$ ' to be the right parenthesis ) and $g$ to be a tautology $\mathrm{T}$, we have

$\mathrm{Cl}=($ if $\mathrm{p} .(\mathrm{q}$ and $\mathrm{T})) \Leftrightarrow($ if $\mathrm{p} . \mathrm{T})$, hence

$\mathrm{Cl}=$ (if $\mathrm{p} . \mathrm{q}$ )

$\Leftarrow$ : Suppose that $\mathrm{Cl}=$ (if $\mathrm{p}$. q). Then for each proposition $g, \mathrm{Cl}=$ (if $\mathrm{p}$. (q

and $\mathrm{g}$ )) $\Leftrightarrow$ (if $\mathrm{p} . \mathrm{g}$ ), and thus for any good final $b^{\prime}, \quad \mathrm{Cl}=[$ (if $\mathrm{p}$. (q and $\mathrm{g}$ )

$\left.\mathrm{b}^{\prime}\right] \Leftrightarrow[$ (if p. g b']. 
Since ( $p$ or $q q^{\prime}$ ) has the same bivalent semantics as (if (not $\left.p\right) . q q^{\prime}$ ), and since $p$ and $q q^{\prime}$ appear in the same order in the two constructions, the Transparency theory also predicts that ( $p$ or $q q^{\prime}$ ) should have the same presupposition as (if (not $p$ ) . $q q^{\prime}$ ), namely (if $p . q$ ) (see Schlenker 2008s for discussion). Thus we have now explained why the negation of the first disjunct can justify the presupposition of the second. This derives on principled grounds the asymmetric dynamic disjunction which was posited in Beaver 2001. It is worth noting that all the explanatory accounts we survey here make exactly the same prediction in this respect.

Finally, let us consider a quantificational example. As noted, Each of my students has stopped smoking and None of my students have stopped smoking both presuppose that each of my students used to smoke. The universal inference obtained in the case of none is particularly important because it is characteristic of presuppositions - neither entailments nor scalar implicatures give rise to such a pattern (see Chemla, to appear a, for discussion and experimental data). Let us see how this result can be derived.

(17) (No P . QQ Q') presuppoes (Every P .Q )

a. Transparency requires that for each clause $g$ and each good final $b$, $\mathrm{Cl}=\left[\left(\right.\right.$ No $\mathrm{P} .(\mathrm{Q}$ and $\left.\mathrm{g}) \mathrm{b}^{\prime}\right] \Leftrightarrow[$ (No P . g b']

b. Claim: Transparency is satisfied $\Leftrightarrow \mathrm{Cl}=($ Every $\mathrm{P} . \mathrm{Q})$

c. Proof

$\Rightarrow$ : Suppose that it is not the case that $\mathrm{Cl}=($ Every $\mathrm{P} . \mathrm{Q})$. Then for some world $\mathrm{w}$ and individual d, $\mathbf{P}(\mathrm{w})(\mathrm{d})=1$ but $\mathbf{Q}(\mathrm{w})(\mathrm{d})=0$. Take $g$ to be a predicate $D^{\prime}$ which is true of $\mathrm{d}$ and nothing else in w, and take $b^{\prime}$ to be ). In such a case, $w \mathrm{l}=\left(\right.$ No $\mathrm{P}$. (Q and D')) because the only member of $\mathbf{D}^{\prime}(\mathrm{w})$, namely d, does not belong to $\mathbf{Q}(\mathrm{w})$, so that the nuclear scope has an empty extension in $w$. On the other hand, $w \mid \neq$ (No P. D'), because d belongs both to $\mathbf{P}(\mathrm{w})$ and to $\mathbf{D}^{\prime}(\mathrm{w})$.

$\Leftarrow$ : Suppose that $\mathrm{Cl}=$ (Every $\mathrm{P}$. Q). By the Conservativiy of No, for any predicate $g, \mathrm{Cl}=($ No $\mathrm{P} .(\mathrm{Q}$ and $\mathrm{g})) \Leftrightarrow($ No $\mathrm{P} . \mathrm{g})$, hence the result (since the only good final $b$ ' is the right parenthesis).

\subsection{General Results}

It was shown in Schlenker 2007 that in the propositional case the Transparency theory is fully equivalent to a version of Heim's dynamic semantics (augmented with the asymmetric dynamic disjunction of Beaver 2001). In the quantificational case, the equivalence holds only if two additional assumptions are made:

-Non-Triviality: quantificational clauses should not be 'trivial' (i.e. replaceable with a tautology or a contradiction).

-Constancy: the domain is finite, and in addition restrictors should hold true of a constant number of individuals throughout the context set. 
These assumptions are stated precisely in Schlenker 2007, to appear (Appendix III). Let us just recapitulate the main conclusion, writing as $C[F]$ the update of $\mathrm{C}$ with $F$ in Heim's framework ${ }^{3}$ :

(18) Under the assumptions of Non-Triviality and Constancy,

a. $\mathrm{C}[\mathrm{F}] \neq \#$ iff $\operatorname{Transp}(\mathrm{C}, \mathrm{F})$.

b. If $\mathrm{C}[\mathrm{F}] \neq \#, \mathrm{C}[\mathrm{F}]=\{\mathrm{w} \in \mathrm{C}: \mathrm{w} \mathrm{l}=\mathrm{F}\}$

\subsection{Assessment}

The Transparency theory addresses the Explanatory Challenge defined at the beginning of our discussion (in (4)). But several reasonable criticisms have been leveled against it.

1. First, it inherits some of the empirical deficiencies of Heim's analysis. (i) When the assumptions of Non-Triviality and Constancy are met, the analysis predicts that universal inferences should systematically be obtained when a trigger is embedded in the nuclear scope of a generalized quantifier. But as we saw in Section 2, significant differences are in fact found among quantifiers; why this is so is unclear given the present analysis. (ii) Universal inferences are also predicted when a trigger appear in the restrictor of a quantifier; and here Chemla's data suggest that the prediction is incorrect; we revisit this issue at the end of this article (we will see that universal inferences are plausibly obtained, but with other triggers).

2. Second, Be Articulate has been criticized either because (i) it lacks motivation (Beaver 2008, Krahmer 2008, van der Sandt 2008), or because (ii) it leads to undesirable predictions in case the articulated competition ... (d and $\left.\underline{d} d^{\prime}\right) \ldots$ is ungrammatical, or implausibly complicated (Beaver 2008). A discussion is found in Schlenker 2008b; let us sketch the main points.

(i) First, there is arguably some independent motivation for Be Articulate; some cases of adjectival modification arguably lead to deviance because they violate $B e$ Articulate:

\footnotetext{
${ }^{3}$ In Schlenker 2007, to appear, the following semantics is assumed for Heim's analysis (the parts inside $<>$ are optional; and $Q_{i}$ is a generalized quantifier whose semantics is given by the 'tree of numbers' $\left.f_{i}\right)$ :

$\mathrm{C}[\mathrm{p}]=\left\{\mathrm{w} \in \mathrm{C}: \mathbf{p}^{\mathrm{w}}=1\right\}$

$\mathrm{C}\left[\mathrm{pp}^{\prime}\right]=\#$ iff for some $\mathrm{w} \in \mathrm{C}, \mathbf{p}^{\mathrm{w}}=0$; if $\neq \#, \mathrm{C}\left[\mathrm{pp} \mathrm{p}^{\prime}\right]=\left\{\mathrm{w} \in \mathrm{C}: \mathbf{p}^{\mathrm{\prime w}}=1\right\}$

$\mathrm{C}[(\operatorname{not} \mathrm{F})]=\#$ iff $\mathrm{C}[\mathrm{F}]=\#$; if $\neq \#, \mathrm{C}[(\operatorname{not} \mathrm{F})]=\mathrm{C}-\mathrm{C}[\mathrm{F}]$

$\mathrm{C}[(\mathrm{F}$ and $\mathrm{G})]=\#$ iff $\mathrm{C}[\mathrm{F}]=\#$ or $(\mathrm{C}[\mathrm{F}] \neq \#$ and $\mathrm{C}[\mathrm{F}][\mathrm{G}]=\#)$; if $\neq \#, \mathrm{C}[(\mathrm{F}$ and $\mathrm{G})]=\mathrm{C}[\mathrm{F}][\mathrm{G}]$

$\mathrm{C}[(\mathrm{F}$ or $\mathrm{G})]=\#$ iff $\mathrm{C}[\mathrm{F}]=\#$ or $(\mathrm{C}[\mathrm{F}] \neq \#$ and $\mathrm{C}[\operatorname{not} \mathrm{F}][\mathrm{G}]=\#)$; if $\neq \#, \mathrm{C}[(\mathrm{F}$ or $\mathrm{G})]=\mathrm{C}[\mathrm{F}] \cup$

$\mathrm{C}[\operatorname{not} \mathrm{F}][\mathrm{G}]$

$\mathrm{C}[($ if $\mathrm{F}$. G) $]=\#$ iff $\mathrm{C}[\mathrm{F}]=\#$ or $(\mathrm{C}[\mathrm{F}] \neq \#$ and $\mathrm{C}[\mathrm{F}][\mathrm{G}]=\#)$; if $\neq \#, \mathrm{C}[($ if F.G) $]=\mathrm{C}-\mathrm{C}[\mathrm{F}][$ not G]

$\mathrm{C}\left[\left(\mathrm{Q}_{\mathrm{i}}<\underline{\mathrm{P}}>\mathrm{P}^{\prime} .<\underline{\mathrm{R}}>\mathrm{R}^{\prime}\right)\right]=\#$ iff $<$ for some $\mathrm{w} \in \mathrm{C}$, for some $\mathrm{d} \in \mathrm{D}, \mathbf{P}^{\mathrm{w}}(\mathrm{d})=0>$ or $<$ for some $\mathrm{w} \in \mathrm{C}$, for some $\mathrm{d} \in \mathrm{D},<\mathbf{P}^{\mathrm{w}}(\mathrm{d})=1$ and $>\mathbf{P}^{\prime \mathrm{w}}(\mathrm{d})=1$ and $\mathbf{R}^{\mathrm{w}}(\mathrm{d})=0>$. If $\neq \#, \mathrm{C}\left[\left(\mathrm{Q}_{\mathrm{i}}<\mathrm{P}>\mathrm{P}^{\prime} .<\mathrm{R}>\mathrm{R} '\right]\right)=\{\mathrm{w} \in$ C: $\left.\mathrm{f}_{\mathrm{i}}\left(\mathrm{a}^{\mathrm{w}}, \mathrm{b}^{\mathrm{w}}\right)=1\right\}$ with $\mathrm{a}^{\mathrm{w}}=\left\{\mathrm{d} \in \mathrm{D}: \mathbf{P}^{\mathrm{w}}(\mathrm{d})=1\right.$ and $\left.\mathbf{R}^{\mathrm{w}}(\mathrm{d})=0\right\}, \mathrm{b}^{\mathrm{w}}=\left\{\mathrm{d} \in \mathrm{D}: \mathbf{P}^{\prime \mathrm{w}}(\mathrm{d})=1\right.$ and $\left.\mathbf{R}^{\prime \mathrm{w}}(\mathrm{d})=1\right\}$
} 
(19)a. ? John is an autistic chemist.

b. John is autistic, and he is a chemist.

c. John is an autistic child ${ }^{4}$.

In these cases, one presumably obtains deviance rather than a presupposition because if it were presupposed that, say, John is a chemist, one would save on words by saying John is autistic rather than John is an autistic chemist. The case of adverbial modification is minimally different because adverbs cannot be predicated of a DP in the absence of a verb; and there one can argue that weakened presuppositional effects are indeed found, for instance in None of these ten students came late (inference: each of these ten students came). These conclusions were confirmed with experimental means in Chemla (to appear b).

(ii) Second, consider the case in which the 'articulated' competitor is ungrammatical, or too complex to utter. Beaver 2008 cites as an example of the first case ?Mary is thinner than there is a King of France and he is fat, which should be the 'articulated' version of Mary is thinner than the King of France is fat; since the former is ungrammatical, the latter should be acceptable without a presupposition, which does not seem to be the case ${ }^{5}$. The theory must be weakened to deal with these examples. There are two ways to do so. One is to stick to the principle of Transparency while abandoning the pragmatic principles that motivate it. Another is to stick to the pragmatic principles, but to take them to be encapsulated. Specifically, we could posit that Be Articulate is a principle that does not have access to all rules of grammar, with the result that it treats some ungrammatical sentences as if they were acceptable. There might well be similar cases of encapsulation in the domain of scalar implicatures: for me, There were delegates from New York at the meeting yields an inference that not all delegates from New York were at the meeting, despite the fact that the corresponding alternative is ungrammatical (all - or for that matter most - is not an intersective quantifier, and thus one cannot say There were all delegates from

\footnotetext{
4 Note that the semantic nature of the noun crucially matters, which suggests that the phenomenon does indeed have to do with the excessive richness of the meaning expressed. Here are two further examples from Schlenker 2006:

$$
\begin{aligned}
& \text { a. ? John is a suicidal oncologist. } \\
& \text { b. John is an oncologist and he is suicidal. } \\
& \text { c. John is a suicidal student. }
\end{aligned}
$$

a. ? John is a parricidal linguist.

b. John is a linguist. He is a parricide.

c. John is a parricidal adolescent.

5 Yasutada Sudo (p.c.) independently raised a similar problem with respect to (i)b, which should be the articulated version of (i)a; he suggested a modification of Be Articulate to deal with the problem.

(i) a. John met a man [who knows the king of France very well].

b. *John met a man [who there is a king of France and knows the king of France very well].
} 
New York at the meeting). Whether this approach is promising will have to be determined in future research.

\section{Reconstructing Local Contexts}

An alternative way to address the Explanatory Challenge is to preserve the notion of local contexts, but to provide a general algorithm that predicts their value on the basis of the syntax and the bivalent semantics of any sentence. Stalnaker 1974 attempted to do precisely this, but we saw that a difficulty with his approach was that he equated local contexts with belief states - which made it difficult to account for presupposition projection at the sub-propositional level. A pragmatic reconstruction using different notions is attempted in Schlenker (2009, to appear). Conceptually, the theory is rather close to Stalnaker's, and quite different from the Transparency theory; technically, however, it turns out to be very close to the latter - with the result that it makes almost the same predictions.

\subsection{Motivating Local Contexts}

We take the local context of an expression $S$ to be the minimal domain of objects that the interpreter needs to consider when he attempts to compute the meaning of a sentence. How can this notion of 'minimal domain' be motivated? The interpreter's task is to determine which worlds of the context set are compatible with the speaker's claim; in other words, he must compute a function from worlds in the context set to truth values. To do so, he has access to the context set $\mathrm{C}$, and to the meaning of the words, which we take for simplicity to be functions of various types. Now we will assume (i) that it is easier to perform the steps of the computation when part of the domain of a function can be disregarded, (ii) that the interpretation is performed incrementally (from left to right), and (iii) that before processing any expression, the interpreter tries to simplify his task as much as possible given what he already knows about the meaning of the sentence. From these assumptions, it follows that the interpreter will try to decide in advance of interpreting any expression $S$ what is the smallest domain he needs to consider when he assesses the meaning of $E$; this 'smallest domain' is our notion of local context.

Let us make the intuition clear with an example. Suppose that we are in a context $\mathrm{C}$, and that we have heard the speaker say: If John used to smoke, ... . Having computed the meaning of the antecedent, we set out to compute the meaning of the consequent $S$ of this conditional, analyzed as before as a material implication. One strategy would be to retrieve a function that specifies the value of $S$ in all possible worlds. But for the purposes of the conversation, only the worlds in $\mathrm{C}$ matter, because all other worlds are excluded by the shared assumptions of the conversation partners. So instead of computing the meaning of

$S$, the interpreter may retrieve a function that uniformly assigns the value 'false' 
to all worlds outside of $\mathrm{C}$, and which assigns the value of $S$ to those worlds that lie in $\mathrm{C}$; this allows him to disregard part of the domain of the function when he computes the meaning of the expression. In effect, the interpreter may thus compute the value of ( $c^{\prime}$ and $S$ ) instead of the value of $S$, where $c^{\prime}$ denotes $\mathrm{C}$. We will say that this restriction to $c$ ' is 'innocuous', because no matter what the value of $S$ turns out to be, the restriction will not affect the truth conditions of the entire sentence. Still, the interpreter can make his life even easier by further restricting attention to those C-worlds in which John smoked, because all worlds in which John never smoked will make the conditional true no matter what the value of $S$ turns out to be; so if $c^{\prime}$ denotes the set of p-worlds within $\mathrm{C}, c^{\prime}$ will still be an innocuous restriction. We take the local context of $S$ to be the strongest innocuous restriction, i.e. the one that entails all other innocuous restrictions.

\subsection{Definitions}

Let us see more precisely how local contexts are computed. Since presupposition triggers are either of predicative or propositional type, we only need to determine the local context of propositional and predicative expressions. To do so, we enrich the object language with (i) context variables, which may be of propositional or predicative type (they will be written below as $c^{\prime}$ ), and (ii) predicate conjunction, which receives the natural interpretation. If $\mathrm{w}$ is a world and $\mathrm{F}$ is a formula (which may contain the variable $\left.c^{\prime}\right)$, we write $\mathrm{w} \mid={ }^{c^{\prime} \rightarrow \mathrm{x}} \mathrm{F}$ to indicate that $\mathrm{w}$ satisfies the formula $F$ when $c$ ' denotes x (as usual, we extend the notation to sets of worlds: $\mathrm{C} \mid{ }^{\mathrm{c}^{\prime} \rightarrow} \mathrm{x} F$ means that every world in $\mathrm{C}$ satisfies $F$ given this assignment function). We say that a proposition $\mathrm{x}$ is stronger than a proposition $\mathrm{x}$ ' if $\mathrm{x}$ entails $\mathrm{x}$ '; and similarly if $\mathrm{x}$ and $\mathrm{x}$ ' are properties, with a generalized notion of entailment ${ }^{6}$. Our definition of local contexts can now be stated as follows:

(20) The local context (written as $l c\left(C, \underline{d} d^{\prime}, a \_b\right)$ ) of a propositional or predicative expression $d$ that occurs in a syntactic environment $a \_b$ in a context $C$ is the strongest proposition or property $\mathrm{x}$ which guarantees that for any expression $d$ ' of the same type as $d$, for all strings $b$ ' for which $a d^{\prime}$ ' $b$ ' is a well-formed sentence,

$$
C I I^{c^{\prime} \rightarrow x} \quad a\left(c^{\prime} \text { and d') b' } \Leftrightarrow a d^{\prime} b^{\prime}\right.
$$

If no strongest proposition or property $\mathrm{x}$ with the desired characteristics exists, lc $(\mathrm{C}, \underline{\mathrm{dd}}$ ', a_b $)=\#$.

Following the intuition we developed earlier, the local context of $d$ in the sentence $a d b$ is the strongest innocuous restriction that the interpreter can make in

\footnotetext{
6 Writing as $\mathrm{x}^{\mathrm{w}}$ the value of a property $\mathrm{x}$ at $\mathrm{w}, \mathrm{x}$ entails a property $\mathrm{x}$ ' just in case for every possible world $\mathrm{w}$ and individual $\mathrm{d}$, if $\mathrm{d} \in \mathrm{x}^{\mathrm{w}}$, then $\mathrm{d} \in \mathrm{x}{ }^{\mathrm{w}}$.
} 
advance of interpreting $p$ when he processes the sentence from left to right. So at the point at which he computes this local context, he has access to the meaning of the expressions in the string $a$, but not to the meaning of $p$ itself, nor of the expressions that come after $p$ in the string $b$. Our procedure is incremental because it requires that the local context be an innocuous restriction no matter which expressions appear at the end of the sentence. This is the reason the rule in (20) requires that for every $d^{\prime}$ 'and $b^{\prime}, a$ (c' and $d^{\prime}$ ') $b^{\text {' should be equivalent to } a d^{\prime}}$ $b$ ' relative to the context set.

With this notation in place, we can repeat the standard dynamic definition of presupposition satisfaction:

(21)a. An elementary presuppositional expression $\underline{d} d^{\prime}$ is acceptable in a syntactic environment $a \_b$ in a context $C$ (written as: $\operatorname{Sat}\left(C, \underline{d} d^{\prime}, a \_b\right)$ ) just in case d is entailed by the local context of $\underline{d} d^{\prime}$. In other words: $\operatorname{Sat}\left(\mathbf{C}, \underline{d} d^{\prime}\right.$, a_b ) just in case $\mathbf{l c}(\mathbf{C}, \underline{d} d$ ', a_b) entails $\mathbf{d}$.

b. A sentence $F$ is acceptable in a context $\mathrm{C}$ just in case for every expression $\underline{d} d^{\prime}$, for all strings $a, b$, if $\mathrm{F}=\mathrm{a} \underline{\mathrm{dd}}^{\prime} \mathrm{b}$, then $\operatorname{Sat}\left(\mathrm{C}, \underline{\mathrm{dd}}\right.$ ', $\left.\mathrm{a} \_\mathrm{b}\right)$.

\subsection{Examples}

To illustrate, let us compute the local context of $S$ in the complex sentence John used to smoke and $S$. We ask once again what is the smallest domain of worlds that the interpreter may restrict attention to when he starts interpreting $S$. As before, he may exclude from consideration all worlds that are not compatible with C. But now he can do more: any world w in which John never smoked will make the first conjunct false, and thus the value in w of the second conjunct will be immaterial to the conversation. Hence it won't hurt to compute the meaning of $c$ ' and $S$ rather than $S$, where $c$ ' denotes those C-worlds that satisfy the first conjunct. On the other hand, all of these worlds must be considered: if $c$ ' excluded some world $\mathrm{w}$ of $\mathrm{C}$ in which John used to smoke, it could turn out that $S$ is true in w; by computing John used to smoke and (c' and S) rather than John used to smoke and $S$, the interpreter would wrongly conclude that the sentence is false in $\mathrm{w}$. The set of $\mathrm{C}$-worlds that satisfy the first conjunct is thus the strongest innocuous restriction; in other words, it is the local context of the second conjunct. This correctly predicts that John used to smoke and he has stopped smoking does not presuppose anything: by construction, the local context of the second conjunct already entails its presupposition, and so no special demands are made on the global context $\mathrm{C}$.

Since a general result guarantees equivalence with the Transparency theory (and thus with Heim's dynamic semantics), we do not discuss further examples and turn instead to a derivation of the equivalence itself. 


\subsection{Equivalence with the Transparency Theory and with Dynamic Semantics}

Our reconstruction of local contexts does things in two steps:

-it starts by defining the local context of an expression $\underline{d} d$ ' in an environment $a \_b$ as the strongest $c^{\prime}$ for which $c^{\prime}$ is transparent in $a^{c^{\prime}} \mathrm{g} b$ relative to the context set C.

-it then requires that the value of $c^{\prime}$ should entail $\mathbf{d}$ - which means that $d$ is 'locally trivial'.

The Transparency theory does essentially the same thing, but in a single step: given a sentence $a \underline{d} d^{\prime} b$, it simply asks whether $\underline{d}$ is (incrementally or symmetrically) transparent no matter what the assertive component $d$ ' turns out to be. Because the theory is based on a competition between $a \underline{d} d d^{\prime} b$ and its 'articulated' competitor $a$ ( $d$ and $\underline{d} d$ ') $b$, the relevant notion of 'transparency' involves a full conjunction (i.e. we ask whether $d$ and could be eliminated without truth-conditional loss), but the end result is still that the presupposition $d$ must be 'locally trivialy'.

It can be shown that whenever the local context of $\underline{d} d^{\prime}$ ' exists, $\underline{d} d$ ' satisfies Transparency just in case $d$ is entailed by its local context.

(22) Equivalence with Transparency

For every formula that has the form $a \underline{d} d^{\prime} b$, if $1 \mathrm{c}\left(\mathrm{C}, \underline{\mathrm{d} d}{ }^{\prime}, \mathrm{a} \_\mathrm{b}\right) \neq \#$, then Transp(C, dd', a_b) iff $\operatorname{Sat}(C, \underline{d d}$ ', a_b $)$.

The argument is straightforward.

-First, suppose that $\underline{d} d^{\prime}$ satisfies the principle of Transparency in the string $a \_b$ uttered in a context $\mathrm{C}$ (written as: $\operatorname{Transp}\left(C, \underline{d} d^{\prime}, a \_b\right)$ ). Then for every $g$ of the same type as $d$ and for every good final $b^{\prime}, \mathrm{C} \mid=\mathrm{a}(\overline{\mathrm{d}}$ and $\mathrm{g}) \mathrm{b}^{\prime} \Leftrightarrow \mathrm{a} \mathrm{g} \mathrm{b}$. But this also means that $\mathbf{d}$ is a transparent restriction for $\underline{d} d^{\prime}$ ' in $a \_b$. Since the local context of $\underline{d} d^{\prime}\left(=\mathrm{lc}\left(\mathrm{C}, \underline{\mathrm{dd}} \mathrm{d}^{\prime}, \mathrm{a} \_\mathrm{b}\right)\right)$ is the strongest transparent restriction (i.e. the one that entails all others), it immediately follows that $1 c(C, \underline{d d}$ ', a b b) entails d.

-Second, suppose that lc(C, dd', a b) entails d. Since c' denotes this local context, we have the following equivalences:

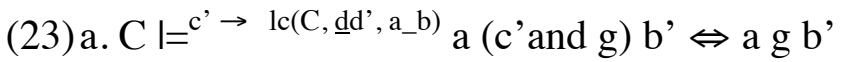

b. $\mathrm{Cl}=\mathrm{c}^{\prime} \rightarrow$ lc(C, dd', a_b) $\mathrm{a}\left(\mathrm{c}^{\prime}\right.$ and $(\mathrm{d}$ and $\left.\mathrm{g})\right) \mathrm{b}^{\prime} \Leftrightarrow \mathrm{a}(\mathrm{d}$ and $\mathrm{g}) \mathrm{b}^{\prime}$

But since $\mathrm{lc}(\mathrm{C}, \underline{\mathrm{dd}}$ ', a $\mathrm{a}$ ) $)$ entails $\mathbf{d}$, replacing $g$ with ( $d$ and $g$ ) in $a$ (c'and $g$ ) $b$ ' won't affect the truth conditions:

$$
\mathrm{Cl} \mathrm{I}^{\mathrm{c}^{\prime} \rightarrow} \mathrm{lc}\left(\mathrm{C}, \underline{d d}^{\prime}, \mathrm{a} \_\mathrm{b}\right) \mathrm{a}\left(\mathrm{c}^{\prime} \text { and }(\mathrm{d} \text { and } \mathrm{g})\right) \mathrm{b} \mathrm{b}^{\prime} \Leftrightarrow \mathrm{a}\left(\mathrm{c}^{\prime} \text { and } \mathrm{g}\right) \mathrm{b}
$$

Since the left-hand sides of (23)b and (24) are identical, we obtain (25):

$$
\mathrm{Cl}=\mathrm{l}^{\mathrm{c}^{\prime} \rightarrow} \mathrm{lc}\left(\mathrm{C}, \underline{d d}^{\prime}, \mathrm{a}_{-} \mathrm{b}\right) \mathrm{a}\left(\mathrm{c}^{\prime} \text { and } \mathrm{g}\right) \mathrm{b}, \Leftrightarrow \mathrm{a}(\mathrm{d} \text { and } \mathrm{g}) \mathrm{b}^{\prime}
$$


And since the left-hand sides of (25) is identical to that of (23)a, we conclude in the end that $\mathrm{C} \mid=^{\mathrm{c}^{\prime}} \rightarrow \operatorname{lc}\left(\mathrm{C}, \mathrm{dd}^{\prime}, \mathrm{a}_{-} \mathrm{b}\right) \mathrm{a}(\mathrm{d}$ and $\mathrm{g}) \mathrm{b}^{\prime} \Leftrightarrow \mathrm{a} \mathrm{g} \mathrm{b}^{\prime}$. Since $c^{\prime}$ does not occur in this formula, the value assigned to $c$ ' is irrelevant and we obtain the result that $\mathrm{C} \mid=\mathrm{a}$ ( $\mathrm{d}$ and $\mathrm{g}$ ) b' $\Leftrightarrow \mathrm{a} \mathrm{g} \mathrm{b}$, which shows that $\underline{d} d^{\prime}$ ' satisfies Transparency.

More generally, it follows that an entire formula $F$ satisfies Transparency just in case each presupposition is entailed by its (incremental or symmetric) local context. Through the (limited) equivalence between the Transparency theory and Heim's dynamic semantics, we also obtain in this way a limited equivalence between the latter and our reconstruction of local contexts.

\subsection{Local Contexts vs. Transparency}

The equivalence isn't quite complete because there are cases in which local contexts fail to exist; in such cases, a refinement of the theory is needed to account for presupposition projection - and the refinement in question yields full equivalence with the Transparency theory (for details, see Schlenker, to appear, Appendices I and III). Modulo this remark, all empirical advantages and flaws of the Transparency theory are inherited by our reconstruction of local contexts.

This is not to say that there is no difference between the two theories.

1. Since our reconstruction of local contexts does not rely on Be Articulate, it is immune to the objections that were leveled against the latter, namely that (a) it is insufficiently motivated, and (b) it makes incorrect predictions in case the 'articulated' competitor is ungrammatical or too complicated to express.

2. Unlike the Transparency theory, an analysis based on local contexts makes it possible to develop a general theory of triviality. We may call 'local meaning' of $E$ the intersection of $\mathbf{E}$ with the local context of $E$. An expression $E$ is locally trivial if the local meaning of $E$ is indistinguishable from that of a tautology or of a contradiction - which is to say that $E$ or (not $E$ ) is entailed by its local context (Stalnaker 1978). This immediately accounts for the pragmatic oddness of the examples in (26): in each case, the expression in bold is either entailed by its local context, or contradictory with it.

(26) a. ? John has cancer and he is sick.

b. ? John is sick or he has cancer.

c. ? No student is a student and proud of it.

Given his analysis of conjunctions, Stalnaker could account for the oddness of (26)a, since he is sick is entailed by its local context. But for lack of a general theory of local contexts, (26)b-c weren't explained. They are in the present framework: in (26)b, he has cancer is contradictory in its local context, which entails the negation of John is sick. In (26)c, a student is entailed by its local context. This analysis could in principle pave the way for a more general theory of triviality. 
3. Last, but not least, the two theories are likely to make different predictions about psycholinguistic data. As was noted in Section 2, Chemla's experiments suggest that subjects who fail to compute a presupposition take more time than those who compute one. This is the opposite from the result typically found about scalar implicatures: a subject who fails to compute a scalar implicature takes less time than one who does compute it. These results have different consequences for the two theories.

-For the Transparency theory, presuppositions are implicatures of manner. So these data might be problematic: the failure to compute a presupposition should have the same effect on reaction times as the failure to compute an implicature. As a first approximation, then, Chemla's data go against the Transparency theory. But in fact the situation is more subtle: the Transparency theory does not claim that presuppositions are scalar implicatures, but rather implicatures of manner. So the question is how the latter affect reaction times: do subjects who fail to compute an implicature of manner take more or less time than those who do compute it? This will have to established in future research.

-On the other hand, our reconstruction of local contexts is in the same situation as dynamic semantics with respect to Chemla's data. It can claim that the normal course of events is for a presupposition to be entailed by its local context; if this is not the case, the presupposition must be cancelled in some way. In Heim's theory, this is done through the mechanism of local accommodation, which is presumably costly; the same general line could be adopted here.

\section{Trivalent theories}

\subsection{Motivating Trivalent theories}

Trivalent analyses of presupposition projection have recently undergone a revival thanks to the works of George 2008a, b and Fox 2008, who follow insights of Peters 1979 and Beaver and Krahmer 2001. Their starting point is a directed version of two trivalent logics, Strong Kleene and Supervaluations. These systems are designed to treat a semantic failure as a kind of uncertainty about the value of an expression: roughly, the idea is that if $p p^{\prime}$ is uttered while $p$ is false, we just cannot determine whether the clause is true or false - although we know it has a classical value. The semantic module outputs the value \# in case this uncertainty cannot be resolved - which systematically happens with unembedded atomic propositions whose presupposition is not met. But in some complex formulas it may happen that no matter how the value of $p p$ ' is resolved (i.e. as true or false), one will be in a position to determine unambiguously the value of the entire sentence. Consider for instance the sentence ( $p$ and $q q^{\prime}$ ) in a situation in which $p$ is false and $q$ is false too. $q q^{\prime}$ 'receives the indeterminate value \#, but no matter how the indeterminacy is resolved, the entire sentence will be false. Now we can make this same reasoning with respect to every world in the context set: for any 
world $\mathrm{w}$, the sentence will have a determinate truth value just in case either (i) $p$ is false at w (so that it doesn't matter how one resolves the indeterminacy of the second conjunct); or (ii) $p$ is true, in which case the presupposition $q$ of the second conjunct is satisfied. Since we are solely interested in worlds that are compatible with what the speech act participants take for granted, we derive the familiar prediction that the context set must guarantee that if $p, q$; this is the condition that must be satisfied if ( $p$ and $q q$ ') is to have a determinate truth value in every world of the context set. The intuition that drives this analysis is completely general: by treating presupposition failure as a kind of 'uncertainty' between true and false, it provides a general recipe for determining under what conditions the uncertainty in question does or does not matter for the entire sentence. This allows these trivalent accounts to the Explanatory Challenge that was stated at the outset.

The trivalent analysis comes in several varieties, depending on whether the semantics is taken to be compositional or not. In the first case, we obtain a directional version of the Strong Kleene logic, one first explored by Peters 1979, and greatly developed by George 2008a, b; in the second case, we naturally obtain a directional version of a supervaluationist semantics (Fox 2008). Roughly speaking, supervaluations treat the semantic uncertainty triggered by an expression $p p^{\prime}$ type by type, in the sense that different occurrences of $p p^{\prime}$ in a given sentence must be 'resolved' in the same way. As a result, all classical tautologies are also supervaluationist tautologies; for instance, even if $p$ is false and thus $p p^{\prime}$ is indeterminate, ( $p p^{\prime}$ or (not $\left.\left.p p^{\prime}\right)\right)$ is evaluated as true, because when we resolve the uncertainty in the same way for both tokens of $p p$ ', we end up with a true statement. By contrast, Strong Kleene treats the semantic uncertainty token by token, with the result that ( $p p^{\prime}$ or (not $\left.p p^{\prime}\right)$ ) gets the value \# when $p p$ ' is indeterminate. For simplicity, we will discuss the Supervaluationist approach discussed in Fox $2008^{7}$.

\subsection{Definitions}

\subsubsection{Supervaluations}

\footnotetext{
7 The strategy we will adopt to make the Supervaluationist framework incremental is as close as possible to the one we used in the Transparency theory and in our reconstruction of local contexts. On the other hand, there are several ways to make a Strong Kleene directional. George 2008a, b bases his analysis on the linear order in which the arguments of a functor appear (he follows in this respect the intuitions of Peters 1979 and Beaver and Krahmer 2001). An alternative would be to start from the Strong Kleene logic, and to adopt the strategy we develop for the supervaluationist semantics, which is to quantify over good finals and to require that no matter how a sentence ends it should have a value different from \#.
} 
Following the Supervaluationist framework, we start from a trivalent valuation, which assigns partial functions to expressions of propositional and predicative type; to obtain a definition of truth and falsity for the entire language, we will consider certain complete (bivalent) extensions of these partial functions. In order to apply this analysis to the fragment we have been using throughout, the trivalent valuation must treat symbols of the form $\underline{p p^{\prime}}$ and $\underline{P} P^{\prime}$ as atomic - but we will specify its semantics in such a way that $p$ is in fact the presupposition of $p p$ ': the latter will get the indeterminate value \# in a world $\mathrm{w}$ whenever $p$ is false in $\mathrm{w}$ (and similarly for predicates of the form $\underline{P} P^{\prime}$, evaluated with respect to a world and an individual). To be more precise, we define in (27) our trivalent valuation i on the basis of the bivalent valuation I we used earlier:

(27) Trivalent valuations

For all symbols of the form $p, p^{\prime}, P, P^{\prime}$, for all worlds $\mathrm{w}$ in $\mathrm{W}$ and objects $\mathrm{d}$ in $\mathrm{D}$,

a. $i(p)(w)=I(p)(w), i\left(p^{\prime}\right)(w)=I\left(p^{\prime}\right)(w)$

b. $i(P)(w)(d)=I(P)(w)(d), I\left(p^{\prime}\right)(w)(d)=I\left(P^{\prime}\right)(w)(d)$

c. $\mathrm{i}\left(\mathrm{pp} \mathrm{p}^{\prime}\right)(\mathrm{w})=1$ iff $\mathrm{I}(\mathrm{p})(\mathrm{w})=\mathrm{I}\left(\mathrm{p}^{\prime}\right)(\mathrm{w})=1 ; \mathrm{i}\left(\mathrm{pp} \mathrm{p}^{\prime}\right)(\mathrm{w})=0$ iff $\mathrm{I}(\mathrm{p})(\mathrm{w})=1$ and $\mathrm{I}\left(\mathrm{p}^{\prime}\right)(\mathrm{w})=0 ; \mathrm{i}\left(\mathrm{p} \mathrm{p}^{\prime}\right)(\mathrm{w})=$ \# otherwise.

d. $\mathrm{i}\left(\underline{P P}^{\prime}\right)(\mathrm{w})(\mathrm{d})=1$ iff $\mathrm{I}(\mathrm{P})(\mathrm{w})(\mathrm{d})=\mathrm{I}\left(\mathrm{P}^{\prime}\right)(\mathrm{w})(\mathrm{d})=1 ; \mathrm{i}\left(\underline{\mathrm{P}}^{\prime}\right)(\mathrm{w})(\mathrm{d})=0$ iff

$\mathrm{I}(\mathrm{P})(\mathrm{w})(\mathrm{d})=1$ and $\mathrm{I}\left(\mathrm{P}^{\prime}\right)(\mathrm{w})(\mathrm{d})=0 ; \mathrm{i}\left(\mathrm{PP}^{\prime}\right)(\mathrm{w})(\mathrm{d})=$ \# otherwise.

Since the analysis crucially relies on the bivalent extensions of a trivalent valuation, we must define this notion. The intuition is that a bivalent extension i' of a trivalent valuation $i$ is obtained by considering all possible resolutions of the indeterminate value $\#$ as 0 or as 1 , while 'keeping' the classical values that $i$ assigns. This leads to the following definition:

(28) Extensions of a trivalent valuation

$\mathrm{i}^{\prime}$ is a bivalent extension of $\mathrm{i}$ just in case for every proposition $\mathrm{p}$ of type $<\mathrm{s}$, $\mathrm{t}>$, for every predicate $\mathrm{P}$ of type $<\mathrm{s},<\mathrm{e}, \mathrm{t}>>$, for every world $\mathrm{w}$ and for every individual of type $d$ :

if $[\mathrm{i}(\mathrm{p})](\mathrm{w}) \neq \#,\left[\mathrm{i}^{\prime}(\mathrm{p})\right](\mathrm{w})=[\mathrm{i}(\mathrm{p})](\mathrm{w})$; otherwise, $\left[\mathrm{i}^{\prime}(\mathrm{p})\right](\mathrm{w}) \in\{0,1\}$ if $[\mathrm{i}(\mathrm{P})](\mathrm{w})(\mathrm{d}) \neq \#,\left[\mathrm{i}^{\prime}(\mathrm{P})\right](\mathrm{d})=[\mathrm{i}(\mathrm{P})](\mathrm{d})$; otherwise, $\left[\mathrm{i}^{\prime}(\mathrm{P})\right](\mathrm{d}) \in\{0,1\}$

Using the bivalent extensions of a trivalent valuation $i$, we can finally extend the latter to a trivalent interpretation $I^{*}$ for the entire language:

(29) Extension to the entire language of a trivalent valuation

Let $\mathrm{F}$ be a formula, interpreted with respect with respect to a trivalent valuation $i$. Then $i$ is extended to an interpretation $I^{*}$ for the entire language by using the following rules, together with a classical semantics to extend the bivalent valuations i' to the entire language. For every world w,

$\left[\mathrm{I}^{*}(\mathrm{~F})\right](\mathrm{w})=1$ iff for every bivalent extension i’ of $\mathrm{i},\left[\mathrm{i}^{\prime}(\mathrm{F})\right](\mathrm{w})=1$ 
$\left[I^{*}(\mathrm{~F})\right](\mathrm{w})=0$ iff for every bivalent extension i' of $\mathrm{i},\left[\mathrm{i}^{\prime}(\mathrm{F})\right](\mathrm{w})=0$

$\left[\mathrm{I}^{*}(\mathrm{~F})\right](\mathrm{w})=\#$ otherwise.

A sentence $F$ can then be said to be presuppositionally acceptable with respect to a context set $\mathrm{C}$ just in case for every world $\mathrm{w}$ in $\mathrm{C},\left[\mathrm{I}^{*}(\mathrm{~F})\right](\mathrm{w}) \neq \#$. In other words, $\mathrm{C}$ should guarantee that $F$ has a classical value. This leads us to the following definition of 'acceptability', which we call 'symmetric' because it does not (yet) incorporate a left-right bias:

(30) Symmetric Acceptability

A sentence $\mathrm{F}$ uttered in a context $\mathrm{C}$ is symmetrically acceptable if and only if for every world $\mathrm{w}$ of $\mathrm{C},\left[\mathrm{I}^{*}(\mathrm{~F})\right](\mathrm{w}) \neq \#$

\subsubsection{Incrementalization}

At this point, nothing in this trivalent analysis accounts for the difference between the presuppositional behavior of, say, ( $p$ and $\left.q q^{\prime}\right)$ and $\left(q q^{\prime}\right.$ and $p$ ): in supervaluations as in classical logic - or for that matter in Strong Kleene logic - a conjunction is semantically symmetric. Peters 1979 and George 2008a, b made the Strong Kleene rules asymmetric. Peters just stipulated certain rules, but George gave a general recipe for obtaining 'incremental' versions of Strong Kleene operators given a specification of their classical semantics, and the syntactic order in which they take their arguments; this allowed him to fully address the Explanatory Challenge. In the Supervaluationist framework, we can use exactly the same procedure of incrementalization as we did in the Transparency theory: for a trigger $\underline{d} d$ ' to be acceptable in an environment $a \_b$, one should be certain that it will not trigger a failure no matter how the sentence ends. In other words, we should ascertain that for every good final $b$, the sentence $a \underline{d} d$ ' $b$ ' will be acceptable:

Incremental Acceptability

$\mathrm{F}$ uttered in $\mathrm{C}$ is incrementally acceptable just in case for all strings $a, b$, and for expressions $\underline{d} d^{\prime}$, if $F=a \underline{d} d^{\prime} b$, then for every good final b' which contains no underlined material, $a \underline{d} d^{\prime} b^{\prime}$ is presuppositionally acceptable, i.e. for every world $w$ of $C,\left[I^{*}\left(a \underline{d} d^{\prime} b^{\prime}\right)\right](w) \neq \#$.

It should be noted that the incrementalization strategy adopted here is somewhat counterintuitive. As in earlier accounts, the idea is that when we process $\underline{d} d$ ' we should check that no matter how the sentence ends the result should be presuppositionally acceptable; but crucially we consider good finals that do not contain any presuppositional material, as is indicated in bold in (31). If we considered all possible good finals, most sentences that are intuitively acceptable 
would be predicted to be deviant; for instance, ( $p p^{\prime}$ and q) would typically not be acceptable even if the context set entails $p$, because when one checks ( $p p$ ' one would have to consider a sentence such as ( $p p^{\prime}$ and $\left.r r^{\prime}\right)$ - whose presupposition would fail to be satisfied if $\mathrm{C}$ doesn't guarantee that if $p$ ', $r$. This explains the restriction to good finals that only include bivalent (i.e. non-underlined) material in (31).

\subsection{Examples}

To illustrate the theory, we will consider two examples in detail: (if $p . q q$ ') and (No P. QQ') (we informally discussed ( $p$ and $q q^{\prime}$ ) when we motivated the trivalent approach above; we will informally discuss numerical quantifiers below). Since in each case the presupposition trigger is at the end, we do not need to worry about the incremental component of the analysis (this is because at the point at which the presupposition trigger is processed, the only good final will always be the right parenthesis).

\section{(if $\mathbf{p} \cdot \underline{\mathbf{q q}} \mathbf{q}^{\prime}$ )}

a. Claim: This sentence is incrementally acceptable $\Leftrightarrow \mathrm{Cl}=$ (if $\mathrm{p} . \mathrm{q})$

b. Proof:

$\Rightarrow$ : Suppose that the sentence is incrementally acceptable. For every good final $b^{\prime}$, it should be the case that for every world $\mathrm{w}$ of $\mathrm{C}, \mathrm{I}^{*}$ ((if $\mathrm{p}$. qq' b')(w) $\neq \#$; since $b^{\prime}$ can only be $)^{8}$, this is equivalent to: I*((if $\mathrm{p}$. qq' )$)(\mathrm{w}) \neq \#$. Now assume, for contradiction, that $\mathrm{w} \in \mathrm{C}, \mathrm{i}(\mathrm{p})(\mathrm{w})=1$ and $i(q)=0$. It follows that $i\left(q^{\prime}\right)(w)=\#$. Now we can find two bivalent extensions i' and i" of i which satisfy $i(p)(w)=i^{\prime}(p)(w)=i ”(p)(w)$, $i^{\prime}\left(q^{\prime}{ }^{\prime}\right)(w)=1$ and $i^{\prime \prime}\left(q^{\prime} q^{\prime}\right)(w)=0$. It is clear that $i^{\prime}\left(\right.$ if $\left.p \cdot q q^{\prime}\right)(w)=1$, while $i$ '(if $p$. qq') $(w)=0$. Since these two extensions of $i$ disagree, $I^{*}$ (if $\left.\mathrm{p} \cdot \mathrm{qq}^{\prime}\right)(\mathrm{w})=\#$.

$\Leftarrow$ : Suppose that $\mathrm{Cl}=$ (if $\mathrm{p} . \mathrm{q})$. Then for every world $\mathrm{w}$ in $\mathrm{C}$, if $\mathrm{i}\left(\mathrm{qq} \mathrm{q}^{\prime}\right)(\mathrm{w})$ $=\#$, i.e. if $\mathrm{i}(\mathrm{q})(\mathrm{w})=0$, it must be that $\mathrm{i}(\mathrm{p})(\mathrm{w})=0$; and it follows that for every bivalent extension i' of i, either i'(qq')(w) $\neq$ \# (hence i'((if $p$. $\left.\left.\left.\mathrm{qq}^{\prime}\right)\right)(\mathrm{w}) \neq \#\right)$ or or $\mathrm{i}^{\prime}(\mathrm{p})(\mathrm{w})=0$ (hence i' $(($ if $\mathrm{p}$. qq'))(w) =1). Either way, i'((if $\left.\left.\mathrm{p} . \mathrm{qq} \mathrm{q}^{\prime}\right)\right)(\mathrm{w}) \neq \#$. Since the only good final for (if $p . q q^{\prime}$ is ), it follows that $I^{*}($ if $p$. q) $\neq \#$.

In our next example, it will be useful to remember that a sentence $F$ is presuppositionally acceptable just in case for every world w of the context $\mathrm{C}, F$ has the value true or the value false in $\mathrm{w}$.

\footnotetext{
8 More precisely: if could only have been introduced by the rule for (if $F . F$ ) in (12)c; and since $p$ and $q$ are formulas, it must be that $\mathrm{b}=$ ).
} 
(33) (No P . QQ')

a. Claim: This sentence is incrementally acceptable $\Leftrightarrow \mathrm{C}=$ (Every $\mathrm{P}$. (Q and (not Q'))) or (Some P . (Q and Q')).

b. Proof:

$\Rightarrow$ : If the sentence is presuppositionally acceptable, then for every world $w$ of $\mathrm{C}, \mathrm{I}^{*}(\mathrm{~F})(\mathrm{w})=1$ or $\mathrm{I}^{*}(\mathrm{~F})(\mathrm{w})=0$.

-Suppose that $I *(F)(w)=1$. We show that $w I=($ Every $P$. ( Q and (not $\left.\left.\left.Q^{\prime}\right)\right)\right)$. Assume, for contradition, that for some $\mathrm{d}$ in $\mathrm{D}, \mathrm{i}(\mathrm{P})(\mathrm{w})(\mathrm{d})=1$, and $\mathrm{i}(\mathrm{Q})(\mathrm{w})(\mathrm{d})=0$ or $\mathrm{i}\left(\mathrm{Q}^{\prime}\right)(\mathrm{w})(\mathrm{d})=1$.

(a) If $\mathrm{i}(\mathrm{Q})(\mathrm{w})(\mathrm{d})=0, \mathrm{i}\left(\mathrm{QQ}^{\prime}\right)(\mathrm{w})(\mathrm{d})=\#$, and thus for some bivalent extension i' of $\mathrm{i}, \mathrm{i}\left(\mathrm{QQ}^{\prime}\right)(\mathrm{w})(\mathrm{d})=0$, which refutes $\mathrm{I}^{*}(\mathrm{~F})(\mathrm{w})=1$, contra hypothesis.

(b) If $\mathrm{i}(\mathrm{Q})(\mathrm{w})(\mathrm{d})=1$ and $\mathrm{i}\left(\mathrm{Q}^{\prime}\right)(\mathrm{w})(\mathrm{d})=1, \mathrm{i}\left(\mathrm{QQ}^{\prime}\right)(\mathrm{w})(\mathrm{d})=1$, and for every bivalent extension i' of i, i' $\left(Q^{\prime}\right)(w)(d)=1$, which refutes $I^{*}(F)(w)=1$, contra hypothesis.

- Suppose that $I^{*}(\mathrm{~F})(\mathrm{w})=0$. We show that $\mathrm{w} \mathrm{l}=\left(\right.$ Some $\mathrm{P} .\left(\mathrm{Q}\right.$ and $\left.\left.\mathrm{Q}^{\prime}\right)\right)$. Assume, for contradiction, that for every $d$ in $D$ for which $i(P)(w)(d)=1$, $i(Q)(w)(d)=0$ or $i\left(Q^{\prime}\right)=0$. So we can find a bivalent extension i' of $i$ that guarantees that, for every d for which $i(P)(w)(d)=1$, i' $\left(Q^{\prime} Q^{\prime}\right)(w)(d)=0$ [if $\mathrm{i}(\mathrm{Q})(\mathrm{w})(\mathrm{d})=0$, i' $\left(\mathrm{QQ}^{\prime}\right)(\mathrm{w})(\mathrm{d})=0$ is a possible value because $\mathrm{i}\left(\mathrm{QQ}^{\prime}\right)(\mathrm{w})(\mathrm{d})=$ $\#$; if $i(Q)(w)(d)=0$ and $i\left(Q^{\prime}\right)=0, i^{\prime}\left(Q^{\prime}\right)(w)(d)=0$ is a possible value because $\left.i\left(Q^{\prime}\right)(w)(d)=0\right]$. It is then clear that $i^{\prime}(($ No $P$. QQ' $))=1$. But this refutes the claim that $\mathrm{I}^{*}(\mathrm{~F})(\mathrm{w})=0$, contra hypothesis.

$\Leftarrow$ : Suppose that $\mathrm{C}=\left(\right.$ Every $\mathrm{P} .\left(\mathrm{Q}\right.$ and $\left(\right.$ not $\left.\left.\left.\mathrm{Q}^{\prime}\right)\right)\right)$ or (Some $\mathrm{P} .\left(\mathrm{Q}\right.$ and $\left.\left.\mathrm{Q}^{\prime}\right)\right)$. Consider any word $\mathrm{w}$ of $\mathrm{C}$.

-Supose that $\mathrm{w} \mathrm{l}=($ Every $\mathrm{P} .(\mathrm{Q}$ and (not Q'$)))$. It follows that for every $\mathrm{d}$ for which $\mathrm{i}(\mathrm{P})(\mathrm{w})(\mathrm{d})=1, \mathrm{i}\left(\mathrm{QQ}^{\prime}\right)=0$ - and the same result holds for all extensions i' of $\mathrm{i}$, hence $\mathrm{I}^{*}(\mathrm{~F})=1$.

-Suppose that $\mathrm{w} \mathrm{I}=\left(\right.$ Some $\mathrm{P} .\left(\mathrm{Q}\right.$ and $\left.\left.\mathrm{Q}^{\prime}\right)\right)$, and let $\mathrm{d}$ be such that $\mathrm{i}(\mathrm{P})(\mathrm{w})(\mathrm{d})=$ $1, i\left(Q^{\prime}\right)(w)(d)=i\left(Q^{\prime}\right)(w)(d)=1$. It follows that $i\left(Q^{\prime}\right)(w)(d)=1$, and this holds for all bivalent extensions $i$ ' of $i$ as well, hence $I^{*}(F)=0$.

It is clear, then, that (No $P$. QQ') does not presuppose that (Every $P$. Q); what is presupposed is quite a bit weaker, which might seem to go against Chemla's experimental results. However these results only provide information about the inferences one can draw from various statements. And even though (Every $P . Q$ ) is not a presupposition of (No $\left.P . Q Q^{\prime}\right)$, it is an entailment of it, in the sense that if (No $P$. QQ') is true, so is (Every $P$. Q). This fact follows from the part in bold in (33)b. The result is rather intuitive: if in some $\mathrm{C}$-world w some $\mathrm{P}$-individual $\mathrm{d}$ failed to satisfy the presupposition $Q$ of the main predicate, there would be uncertainty as to the value that $Q Q$ ' takes in w with respect to d - which means that we couldn't be certain that no P-individual satisfies $Q Q$ ' (since $\mathrm{d}$ is a potential counterexample). We come back below to further tests that will determine whether the universal inference Chemla found with (No $P$. QQ') is an entailment or a presupposition. 
Be that as it may, trivalent accounts have a field day when it comes to some numerical quantifiers. Consider for instance sentences of the form (At least five $P . Q Q^{\prime}$ ) and (Less than five $\left.P . Q Q^{\prime}\right)$. Chemla showed experimentally that these do not trigger an inference that every P-individual is a Q-individual. Trivalent accounts can derive this result. To make things concrete, suppose that there are ten $\mathrm{P}$-individuals, and suppose further that in $\mathrm{w}$ at least five $\mathrm{P}$ individuals satisfy both $Q$ and $Q$ ', while all other P-individuals fail to satisfy $Q$ with the result that the value that $Q Q^{\prime}$ takes with respect to these other individuals in $\mathrm{w}$ is uncertain. Despite this uncertainty, it can be determined that (At least five $P . Q Q^{\prime}$ ) is true and that (Less than five $P . Q Q^{\prime}$ ) is false. So from the assumption that sentence has a classical truth value, it certainly does not follow that every Pindividual is a Q-individual; in other words, we correctly predict that the universal inference should fail to hold.

Still, this analysis comes at a cost: the sentence (Exactly five $P . Q Q$ ') is predicted to entail that every P-individual is a Q-individual, contrary to Chemla's findings. To see this, suppose for contradiction that in $\mathrm{w}$ (Exactly five $P . Q Q$ ') is true while some P-individual d fails to satisfy $Q$ (which means that $\mathrm{i}\left(\mathrm{QQ}^{\prime}\right)(\mathrm{w})(\mathrm{d})$ $=\#$ ). Consider any extension i' of $\mathrm{i}$ which assigns the value true to (Exactly five $P$. $\left.Q Q^{\prime}\right)$, and suppose for concreteness that $\mathrm{i}^{\prime}\left(\mathrm{QQ}^{\prime}\right)(\mathrm{w})(\mathrm{d})=1$ (the case $\mathrm{i}^{\prime}\left(\mathrm{QQ}^{\prime}\right)(\mathrm{w})(\mathrm{d})=0$ is similar $)$. Since $\mathrm{i}\left(\mathrm{QQ}^{\prime}\right)(\mathrm{w})(\mathrm{d})=\#$, there is a bivalent extension $i$ " of $i$ which is identical to $i$ ' except that $i^{\prime \prime}\left(Q_{Q}^{\prime}\right)(w)(d)=0$. But then $i$ " cannot assign the value true to (Exactly five $P . Q Q$ '): this 'exactly' claim is sensitive to the precise number of $\mathrm{P}$-individuals that satisfy $Q Q$ ', and thus a difference of one will necessary matter. So it couldn't be that all bivalent extensions of i yield the same result, contrary to hypothesis.

\subsection{Comparisons and Assessment}

In all the cases we considered, the Trivalent account predicts presuppositions that are never stronger than those of the Transparency theory or of our reconstruction of Local Contexts. Given the fragment we used throughout, some general results can be stated:

\section{(34) Comparisons}

Consider the fragment defined in (12).

a. With respect to its propositional part, the Trivalent theory under consideration predicts the same presuppositions as the theories we considered earlier (Heim's dynamic semantics, Transparency theory, reconstruction of local contexts).

b. In general, the Trivalent theory predicts presuppositions that are equivalent 
or weaker than the presuppositions predicted by the theories we considered earlier ${ }^{9}$ (and it predicts different entailments).

In quantificational examples, the theories we considered earlier all predict - when some technical assumptions are satisfied - that we should obtain universal presuppositions. Things are different in the Trivalent theory: as we saw, for (No $P$ . QQ'), (At least five $P$. QQ'), (Less than five $P$. QQ'), no universal inferences are predicted.

How should we evaluate these results?

-With respect to at least five and less than five, the trivalent account makes better predictions than the alternatives we considered earlier.

-With respect to exactly five, it predicts in most cases a universal inference, which does not seem to be right given Chemla's result. But the alternative accounts we considered earlier also predict a universal inference.

-With respect to sentences of the form (No $P$. QQ'), all accounts under consideration predict universal inferences, but with a different status: for the accounts we considered earlier, the inference is presuppositional: the universal inference is predicted to be satisfied by each world of the context set; for the Trivalent theory, the inference is an entailment: it is predicted to be satisfied by each world compatible with what the speaker believes.

There is a simple way to distinguish between the theories under consideration, however. When (No $P$. QQ') appears in a question, presuppositional inferences should be projected but entailments should not be. Without going into formal details (which depend on one's theory of questions), the idea is that when a question ? $F$ is asked one can assume that $F$ has a classical truth value, but not that $F$ is true (as this would make the question trivial). So we can ask whether the universal inference is in fact preserved in questions:

(35)a. Did none of these ten students stop smoking?

b. Is it true that none of these ten students have stopped smoking?

I believe that the universal inference is in fact preserved, which would be an argument against the trivalent analysis - though this will have to be established more carefully in future research (see Schlenker 2009 for a more detailed discussion of presupposition projection in questions, developed within Krifka's 'structured meanings' framework).

I should point out that Ben George has elegantly addressed this problem within his own trivalent system (George 2008a), which is far more subtle than the one surveyed here. The basic idea is to add to the trivalent analysis a built-in bias for truth, which specifies that the sentence (No $P$. QQ') is (incrementally) ruled out as deviant if the presupposition alone suffices to exclude the possibility that

9 These results follow from the formal analysis developed in the Appendix of the initial version of my paper on "Local Contexts", available online at http://homepages.nyu.edu/ p pds4/. 
the sentence will end up true. If at some world w of the context set, some element $\mathrm{d}$ satisfies $P$ but not $Q$, we can be certain that the sentence won't be true at w: $\mathrm{d}$ will make $Q Q$ ' indeterminate, which in turn means that the quantified statement may be indeterminate or false, but certainly not true. Importantly, for quantifiers that are not universal in force, some weaker presuppositions are sometimes obtained - arguably an important virtue when one considers Chemla's recent experimental results.

With respect to the reaction times analyzed by Chemla, the Trivalent account is potentially at an advantage over the Transparency theory. The latter takes presuppositions to be implicatures of manner, which makes it mysterious why subjects take less time when they fail to compute an implicature that when they do compute it (as was mentioned before, precisely the opposite result holds of scalar implicatures). Since the trivalent analysis takes presuppositions to be a core semantic property of lexical items, it is not particularly surprising that some costly process should be needed to 'get rid' of them, i.e. to somehow turn them into part of the assertive component. How this process happens is left open - but since alternative accounts also need a stipulation, this is not an argument against the trivalent analysis.

Finally, I note that on a conceptual level the incrementalization strategy adopted within the Trivalent analysis has a weird twist: although the semantics is trivalent, when we quantify over good finals to obtain an incremental projection algorithm we only consider good finals that contain no presupposition triggers. Why this is so is a bit mysterious.

\section{Constrained Dynamic Semantics}

Going full circle, one could try to address the Explanatory Challenge within dynamic semantics itself. Two recent accounts introduce constraints on possible dynamic operators so as to solve the problem of overgeneration that was found in Heim's theory. This program was developed independently, and in rather different forms, by N. LaCasse and D. Rothschild; we focus on the latter. But in order to see what is characteristic of this attempt, we start by adapting our reconstruction of local contexts to a framework which is truly dynamic and yet solves the explanatory problem.

\subsection{A solution based on our reconstruction of local contexts}

Our reconstruction of local contexts is non-dynamic, in the sense that it analyzes the meaning of sentences in terms of truth conditions rather than in terms of context change potentials. Still, one can use it to constrain a more conservative version of dynamic semantics, one in which all expressions are intrinsically dynamic. We can thus require that for any unary connective *, lexical rules specify that the presupposition of $\underline{F} F^{\prime}$ in $\left.\mathrm{C}^{*} \underline{F} F^{\prime}\right]$ should be checked with respect 
to the incremental context of $\underline{F} F^{\prime}$; and in case no presupposition failure occurs, the update of $\mathrm{C}$ with $\left({ }^{*} \underline{F} F^{\prime}\right)$ is simply the subset of worlds of $\mathrm{C}$ that satisfy $\left({ }^{*} F^{\prime}\right)$ (given that in such a case $F$ is entailed by the incremental context, this is the same thing as satisfying $\left.\left({ }^{*} \underline{F} F^{\prime}\right)\right)$.

$$
\begin{aligned}
& \mathrm{C}\left[\left({ }^{*} \underline{\mathrm{F} F}\right)\right]=\# \text { iff } \operatorname{lc}\left(\mathrm{C}, \underline{\mathrm{FF}} \mathrm{F}^{\prime},{ }_{-}\right) \leq \mathbf{F} \text {. If } \neq \#, \mathrm{C}\left[\left({ }^{*} \underline{\mathrm{FF}} \mathrm{F}^{\prime}\right)\right]=\left\{\mathrm{w} \in \mathrm{C}: \mathrm{w} \mathrm{l}=\left(^{*}\right.\right. \\
& \left.\left.\mathrm{F}^{\prime}\right)\right\}
\end{aligned}
$$

The same reasoning can be applied to binary connectives: $\mathrm{C}\left[\left(\underline{\mathrm{FF}}{ }^{\prime} * \mathrm{GG}^{\prime}\right)\right]$ is defined just in case the local context of $\underline{F} F^{\prime}$ entails $\mathbf{F}$ and the local context of $\underline{G} G^{\prime}$ entails $\mathbf{G}$. When no failure arises, $\mathrm{C}\left[\left(\mathrm{FF}^{*} * \mathrm{GG}^{\prime}\right)\right]$ is just the set of C-worlds that satisfy $F^{\prime} * G$ '.

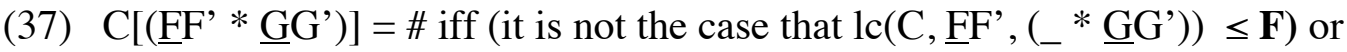
$\left(\operatorname{lc}\left(\mathrm{C}, \mathrm{FF}^{\prime},\left({ }^{*} \mathrm{GG}^{\prime}\right)\right) \leq \mathbf{F}\right.$ and (it is not the case that $\mathrm{lc}\left(\mathrm{C}, \mathrm{GG}^{\prime},\left(\mathrm{FF}^{\prime} *\right.\right.$ $\left.\left.\left.\left.\_\right)\right) \leq \mathbf{G}\right)\right)$. If $\neq \#, C\left[\left(\underline{F F}^{\prime} * \underline{G G}^{\prime}\right)\right]=\left\{w \in C: w l=\left(F^{\prime} * G^{\prime}\right)\right\}$.

To illustrate, for * = and, $\mathrm{C}\left[\left(\underline{F F}^{\prime}\right.\right.$ and $\left.\left.\underline{G G}^{\prime}\right)\right]=\#$ iff the local context of $\underline{F} F^{\prime}$, namely $\mathrm{C}$ itself, fails to entail $\mathbf{F}$, or if the local context of $\underline{G} G^{\prime}$, namely $\mathrm{C} \wedge \underline{\mathbf{F}} \mathbf{F}^{\prime}$, fails to entail G. If $\mathrm{C}\left[\left(\underline{F F}^{\prime}\right.\right.$ and $\left.\left.\underline{G}^{\prime}\right)\right] \neq \#$, it is equal to the set of worlds in $\mathrm{C}$ which satisfy $F^{\prime}$ and $G^{\prime}$. This is exactly the dynamic rule posited in Heim 1983. More generally, our templates derive Heim's results in the propositional case (augmented with the asymmetric dynamic disjunction of Beaver 2001). The template in (37) can easily be extended to binary connectives that have a different syntax, such as (if $F . G$ ) or $(Q F . G)$.

Proponents of dynamic semantics may adopt this implementation of our reconstruction of local contexts. But since in the cases we considered the same results can be obtained within a non-dynamic semantics, it would seem that additional arguments (maybe from other domains, such as anaphora) would be needed to justify the adoption of a dynamic framework.

\subsection{Rothschild's analysis}

\subsubsection{Motivations}

An alternative, laid out in Rothschild 2008a, b, is to develop in greater detail the original intuition of Heim's dynamic semantics, but with a general procedure to 'dynamicize' the classical semantics of any connective or operator. The incremental version of Rothschild's analysis has three components.

1. First, he sets up a formal language in which all Context Change Potentials can be rigorously defined. One can think of it as a meta-language interpreted according to a variant of the Weak Kleene logic: whenever an expression is semantically undefined, so is the sentence it occurs in. This was arguably the tacit assumption made by Heim 1983 when she wrote definitions such as (38) (copied with a slightly updated notation): 
(38) $\mathrm{C}[$ not $\mathrm{S}]=\mathrm{C}-\mathrm{C}[\mathrm{S}]$

The idea was that as soon as any component of $C-C[S]$ is semantically undefined, so is the entire expression; this lead to the desirable result that the presuppositions of $S$ are inherited by not $S$. Rothschild adopts the same idea, but his language is propositional rather than set-theoretic. So for him the definition in (38) would be written as in (39), interpreted with a Weak Kleene logic.

(39) $\mathrm{C}[$ not $\mathrm{S}]=\mathrm{C}$ and not $\mathrm{C}[\mathrm{S}]$

2. Second, Rothschild makes explicit what it means for such a definition to 'correspond' to the semantics of a classical connective. He does so by requiring that in the bivalent case (i.e. when the arguments of the connective do not include presupposition triggers), the right truth conditions are obtained - an idea we also used above when we 'dynamicized' our reconstruction of local contexts: when $F$ and $G$ are non-presuppositional, $\mathrm{C}\left[\left({ }^{*} \mathrm{~F}\right)\right]$ should be the set of $C$-worlds that satisfy the classical meaning of $* F$, and $\mathrm{C}[(\mathrm{F} * \mathrm{G})]$ should be the set of $C$-worlds that satisfy the classical meaning of $\left(F^{*} G\right)$. This still yields many possible dynamic extensions for any classical connective.

3. Third, Rothschild applies a procedure of 'incrementalization' that rules out all but one of these dynamic extensions - which suffices to derive precisely Heim's results, at least in the propositional case.

\subsubsection{Definitions}

Let us turn to Rotschild's definitions in the propositional case (we discuss a slightly simplified version of his system). In what follows, $*$ is a classical connective, e.g. and, or, etc. We start with the formulas from which the dynamic lexical entry of a classical connective * will be defined. Instead of Heim's operations of set-theoretic intersection $(\mathrm{A} \cap \mathrm{B})$, union $(\mathrm{A} \cup \mathrm{B})$ and subtraction (A-B), we use Weak Kleene conjunction, disjunction, and a special operation which we write as $n o t^{C}$, which is the propositional equivalent of complementation within $\mathrm{C}$.

(40) Syntax: definitions for $\mathrm{C}[\mathrm{X} * \mathrm{Y}]$

a. $\mathrm{C}$ is a definition

b. If $\mathrm{C}^{\prime}$ is a definition, $\mathrm{C}^{\prime}[\mathrm{X}]$ and $\mathrm{C}^{\prime}[\mathrm{Y}]$ are definitions

c. If C' and C" are definitions, so are (C' and C"), (C' or C'), and $\operatorname{not}^{\mathrm{C}} \mathrm{C}^{\prime} 10$

(if $\mathrm{C}$ is a tautology $\mathrm{T}$, we write not $C^{\prime}$ instead of $n o t^{T} C^{\prime}$ )

10 Rothschild uses not, which we replace with not $^{C}$; the latter is intended to correspond to Heim's operation $\mathrm{C}-\mathrm{F}$ (= complementation within $\mathrm{C}) . n^{-{ }^{C}}{ }^{C} C^{\prime}$ can be taken as an abbreviation of $(C$ and not $C^{\prime}$ ), or its semantics can be defined directly, as is done below. 
To illustrate: $C, C[X], C[Y], C[Y][X]$ are definitions for $\mathrm{C}[\mathrm{X}$ or $\mathrm{Y}]$. On the other hand, $C[X$ or $Y]$ itself is not a definition because (40) specifies that only the atomic elements $X$ and $Y$ can occur within [.]. By contrast, $(C[X]$ or $C[Y])$ is a definition. $C\left[\right.$ not $\left.^{C} X\right]$ is not a definition either, for the same reason, but $n o{ }^{C} C[X]$ is one.

The semantics is trivalent. For atomic $X, C^{\prime}[X]$ is defined at a world w just in case in every world $C^{\prime}$ entails $X$ - which capture Heim's definedness conditions. The rules for connectives are similar to Weak Kleene (slightly adapted for $\left.n o t^{C}\right)$.

(41) Semantics

We treat $\mathrm{C}$ as a bivalent atomic proposition and $\mathrm{X}$ and $\mathrm{Y}$ as trivalent atomic propositions. We write $\mathbf{E}$ for the value of an expression $E$. The semantics is intensional. For all $\mathrm{w}$ worlds $\mathrm{w}$ :

a. $\mathbf{C}(\mathrm{w})=1$ iff $\mathrm{w} \in \mathbf{C}$.

b. $\mathbf{C}^{\prime}[\mathbf{X}](\mathrm{w})=\#$ unless $\mathbf{C}^{\prime}(\mathrm{w}) \neq \#$ and for all $\mathrm{w}^{\prime}$, if $\mathbf{C}^{\prime}\left(\mathrm{w}^{\prime}\right)=1, \mathbf{X}\left(\mathrm{w}^{\prime}\right) \neq \#$. If $\neq \#, \mathbf{C}^{\prime}[\mathbf{X}](\mathrm{w})=1$ iff $\mathbf{C}^{\prime}(\mathrm{w})=1$ and $\mathbf{X}(\mathrm{w})=1,=0$ otherwise. (Similar rule for Y).

c. The connectives are treated following the Weak Kleene logic, adapted to our special definition of negation:

$\left(\mathbf{C}^{\prime}\right.$ and $\left.\mathbf{C}^{\prime \prime}\right)(\mathrm{w})=\#$ iff $\mathbf{C}^{\prime}(\mathrm{w})=\#$ or $\mathbf{C}^{\prime \prime}(\mathrm{w})=\#$. $\left(\mathbf{C}^{\prime}\right.$ and $\left.\mathbf{C}^{\prime \prime}\right)(\mathrm{w})=1$ iff

$\mathbf{C}^{\prime}(\mathrm{w})=\mathbf{C}^{\prime}(\mathrm{w})=1$

$\left(\mathbf{C}^{\prime}\right.$ or $\left.\mathbf{C}^{\prime \prime}\right)(\mathrm{w})=$ \# iff $\mathbf{C}^{\prime}(\mathrm{w})=$ \# or $\mathbf{C}^{\prime \prime}(\mathrm{w})=\#$. $\left(\mathbf{C}^{\prime}\right.$ or $\left.\mathbf{C}^{\prime \prime}\right)(\mathrm{w})=1$ iff $\mathbf{C}^{\prime}(\mathrm{w})=$ 1 or $\mathbf{C}^{\prime \prime}(\mathrm{w})=1$

$\left(\boldsymbol{n o t}^{\mathrm{C}} \mathbf{C}^{\prime}\right)(\mathrm{w})=$ \# iff $\mathbf{C}^{\prime}(\mathrm{w})=\# .\left(\boldsymbol{n o t}^{\mathrm{C}} \mathbf{C}^{\prime}\right)(\mathrm{w})=1$ iff $\mathbf{C}(\mathrm{w})=1$ and $\mathbf{C}^{\prime}(\mathrm{w})=0$

The next step is the definition of the dynamic extension $u$ of a connective *. Basically, $\mathrm{u}$ is a propositional function which takes arguments $\mathrm{C}, \mathrm{X}, \mathrm{Y}$, and returns a formula of this meta-language which gives the 'right' results in case $X$ and $Y$ are bivalent (non-presuppositional): in such cases, $\mathrm{u}(\mathrm{C}, \mathrm{X}, \mathrm{Y})$ is required to be logically equivalent to $(\mathrm{C}$ and $(\mathrm{X} * \mathrm{Y}))$.

(42) Extensions

Let $*$ a classical binary propositional connective. $\mathrm{u}$ is an extension of $*$ just in case for any (atomic) $\mathrm{C}, \mathrm{X}, \mathrm{Y}$,

(i) $\mathrm{u}(\mathrm{C}, \mathrm{X}, \mathrm{Y})$ is a definition for $\mathrm{C}[\mathrm{X} * \mathrm{Y}]$

(ii) if $\mathrm{X}$ and $\mathrm{Y}$ are bivalent, $\mathrm{I}=(\mathrm{C}$ and $(\mathrm{X} * \mathrm{Y})) \Leftrightarrow \mathrm{u}(\mathrm{C}, \mathrm{X}, \mathrm{Y})$.

At this point, Rothschild's system generates a variety of possible extensions for a given connective. For instance, and has the extensions $\mathrm{u}_{1}, \mathrm{u}_{2}$ and $\mathrm{u}_{3}$ :

Note that, with the intended semantics, $n o t^{C}$ makes it possible to define Heim's Context Change Potential for conditionals:

$\mathrm{C}[($ if X. Y $)]=\mathrm{C}$ and $\operatorname{not}^{\mathrm{C}}\left(\mathrm{X}\right.$ and $\left.\operatorname{not}^{\mathrm{C}} \mathrm{Y}\right)$ 
(43) a. $\mathrm{u}_{1}(\mathrm{C}, \mathrm{X}, \mathrm{Y})=\mathrm{C}[\mathrm{X}][\mathrm{Y}]$

b. $\mathrm{u}_{2}(\mathrm{C}, \mathrm{X}, \mathrm{Y})=\mathrm{C}[\mathrm{Y}][\mathrm{X}]$

c. $\mathrm{u}_{3}(\mathrm{C}, \mathrm{X}, \mathrm{Y})=(\mathrm{C}[\mathrm{X}]$ and $\mathrm{C}[\mathrm{Y}])$

At this point, then, the system overgenerates, as did Heim's theory.

The last step is to make the system incremental; the incremental value $\mathrm{u}^{\mathrm{i}}$ of the extension $\mathrm{u}$ of a connective * yield undefinedness on $\mathrm{u}^{\mathrm{i}}(\mathrm{C}, \mathrm{X}, \mathrm{Y})$ if for some non-presuppositional $\mathrm{Y}^{\prime}, \mathrm{u}\left(\mathrm{C}, \mathrm{X}, \mathrm{Y}^{\prime}\right)=\#$ (as was the case in the trivalent theories we considered above, it is crucial that $Y^{\prime}$ only contain nonpresuppositional material).

(44) Normal and Incremental values

Let $*$ a classical binary propositional connective, and let $\mathrm{u}$ be an extension of *. For any $\mathrm{C}, \mathrm{X}, \mathrm{Y}$,

the normal value of $\mathrm{u}$ is $\mathbf{u}$ itself;

the incremental value $\mathbf{u}^{\mathrm{i}}$ of $\mathrm{u}$ for $\mathrm{C}[\mathrm{X} * \mathrm{Y}]$ is given by: for all $\mathrm{w}$, $\mathbf{u}^{\mathrm{i}}(\mathbf{C}, \mathbf{X}, \mathbf{Y})(\mathrm{w})=$ \# just in case (i) for some non-presuppositional $\mathrm{Y}^{\prime}, \mathbf{u}(\mathbf{C}, \mathbf{X}$, $\left.\mathbf{Y}^{\prime}\right)=\#$, or (ii) $\mathbf{u}(\mathbf{C}, \mathbf{X}, \mathbf{Y})(\mathrm{w})=\#$. If $\neq \#, \mathbf{u}^{\mathrm{i}}(\mathbf{C}, \mathbf{X}, \mathrm{Y})(\mathrm{w})=\mathbf{u}(\mathbf{C}, \mathbf{X}, \mathrm{Y})(\mathrm{w})$.

To see this principle in action, consider again $\mathrm{u}_{1}$ and $\mathrm{u}_{2}$ defined in (43). It is clear that both are extensions of and, and that they may be undefined under different conditions: if $Y$ is non-presuppositional and $\mathrm{C}[\mathrm{X}]=\#, \mathrm{u}_{1}(\mathrm{C}, \mathrm{X}, \mathrm{Y})=\#$, but $\mathrm{u}_{2}(\mathrm{C}$, $\mathrm{X}, \mathrm{Y}$ ), i.e. $\mathrm{C}[\mathrm{Y}][\mathrm{X}]$, may still be defined (if $\mathrm{C}[\mathrm{Y}]$ entails the presupposition of $X$ ). Still, the incremental values of $\mathrm{u}_{1}$ and $\mathrm{u}_{2}$ yield the same result in the case at hand. It is clear that $\mathrm{u}_{1}{ }^{\mathrm{i}}(\mathrm{C}, \mathrm{X}, \mathrm{Y})=\mathrm{u}_{1}(\mathrm{C}, \mathrm{X}, \mathrm{Y})=\#$. What about $\mathrm{u}_{2}{ }^{\mathrm{i}}(\mathrm{C}, \mathrm{X}, \mathrm{Y})$ ? Well, if $\mathrm{Y}^{\prime}$ is a tautology, we have $\mathrm{u}_{2}\left(\mathrm{C}, \mathrm{X}, \mathrm{Y}^{\prime}\right)=\mathrm{C}\left[\mathrm{Y}^{\prime}\right][\mathrm{X}]=\mathrm{C}[\mathrm{X}]=\#$; so fo rsome nonpresuppositional $\mathrm{Y}^{\prime}, \mathrm{u}\left(\mathrm{C}, \mathrm{X}, \mathrm{Y}^{\prime}\right)=\#$, which means that the incremental value of $\mathrm{u}$ is undefined: $\mathrm{u}^{\mathrm{i}}\left(\mathrm{C}, \mathrm{X}, \mathrm{Y}^{\prime}\right)=\#$.

Rothschild 2008a shows that in the propositional case he derives precisely Heim's results. The quantificational case remains to be studied, but it would seem that Rothschild's analysis derives something very close to Heim's universal inferences (as does LaCasse's rather different reconstruction)(.

\subsubsection{Assessment}

Rothschild's theory fully addresses the Explanatory Challenge while preserving all the intuitions of Heim's analysis. It also inherits its empirical weaknesses, which are shared by the Transparency theory and our reconstruction of local contexts. It crucially borrows the incrementalization procedure adopted in the latter theories. But in the cases under study, incrementalization without a dynamic semantics suffices to do all the work - which raises the question why a dynamic implementation should be necessary in the first place.

\section{Symmetric Readings}

Since all the 'new' accounts start with a classical semantics, they derive the left- 
right asymmetries by a separate 'incremental module', which requires that certain principles be satisfied as soon as a trigger is encountered. But this immediately raises the possibility that these asymmetries might be the result of a simple bias possibly due to processing - which can be overcome at some cost. So these theories are compatible with the view that presuppositions can be satisfied 'incrementally', but also, with greater difficulty, 'symmetrically'. In fact, Rothschild 2008a, b explicitly endorses symmetry, and makes it the core of his account; a similar position is adopted by Chemla in his own theoretical analysis of presuppositions (Chemla 2008b), and in Schlenker 2008a, b, to appear (by contrast, Beaver 2008 expresses complete skepticism).

There are well-known arguments in favor of a symmetric account of disjunction, illustrated in (45)a-b; but they extend to conditionals, as seen in (45)a'-b':

(45) a. There is no bathroom or the bathroom is well hidden (after Partee).

b. The bathroom is well hidden or there is a no bathroom.

a'. If there is a bathroom, the bathroom is well hidden.

$\mathrm{b}$ '. If the bathroom is not hidden, there is no bathroom.

(45)a-a' are correctly predicted by dynamic semantics and the incremental version of the preceding accounts to carry no presupposition. By contrast, they predict that (45)b-b' should presuppose that there is a bathroom. The issue is complex and would require a longer discussion (see Schlenker to appear, a, b); but it is plausible that in these examples the presupposition of the first element is justified on the basis of information that appears at the end of the sentence. In fact, when the entire sentence is taken into account, (45)b becomes informationally indistinguishable from (45)a. And similarly for (45)b' and (45)a': trading on the near-equivalence between If not $F$, not $G$ and if $G, F$, when the entire sentence is taken into account, (45)b' becomes informationally similar to (45)a' - which makes it unsurprising that they should transmit presuppositions in the same way.

Although the implementation of symmetry raises some non-trivial issues (see Rothschild 2008b, Beaver 2008 and Schlenker 2008b for discussion), it makes predictions that ought to be tested. Let us consider a specific example. Theories that admit of symmetric readings predict that if not $q q^{\prime}$, not $p$ can (marginally) be understood with the presupposition if $p, q$ - i.e. with the incremental presupposition of if $p, q q^{\prime}$. In recent work conducted by Chemla and myself, we attempted to test this prediction with experimental means. The question is subtle, because we only claim that presuppositions can marginally be satisfied by the symmetric algorithm; in other words, sentences whose presuppositions are symmetrically but not incrementally satisfied should have an intermediate status. In order to obtain acceptability judgments (as opposed to inferences), we explored the behavior of the presupposition trigger too in French ('aussi'), which has the advantage of making accommodation - and in particular local accommodation - very difficult or impossible (see Beaver and Zeevat 2007 
for discussion of why this might be so). This means that when the presupposition of aussi is not satisfied, the resulting sentence is deviant. We asked subjects to rate the acceptability of sentences such as those in (46) ${ }^{11}$ by way of magnitude estimation (for each sentence, they had to click on a bar whose extremes corresponded to 'weird' ( $0 \%$ acceptable) or 'natural' (100\% acceptable)).

(46) L'évolution du salaire des fonctionnaires va être remise à plat.

The evolution of state employees' salaries will be reconsidered.

a1. Si les infirmières sont augmentées, les salaires des enseignants seront eux aussi

\{A. revalorisés / B. bloqués\}.

If the nurses get a raise, the teachers' salaries will THEM too be $\{$ A.

increased / B. frozen\}.

a2. Si les infirmières sont augmentées, les salaires des enseignants seront $\{\mathrm{A}$. revalorisés / B. bloqués\}.

If the nurses get a raise, the teachers' salaries will be $\{$ A. increased /B.

frozen\}.

b1. Si les salaires des enseignants ne sont pas eux aussi \{A. revalorisés / B. bloqués\}, les infirmières ne seront pas augmentées.

If the teachers' salaries are not THEM too $\{$ A. increased / B. frozen $\}$, the nurses won't get a raise.

b2. Si les salaires des enseignants ne sont pas \{A. revalorisés / B. bloqués\}, les infirmières ne seront pas augmentées.

If the teachers' salaries are not $\{A$. increased / B. frozen\}, the nurses won't get a raise.

(46)a1A displays the canonical order if $p$, $q q^{\prime}$, where $p$ entails $q$ : the presupposition of the consequent is satisfied by the antecedent. (46)a1B should be deviant because the presupposition of the consequent is not entailed by the antecedent - in fact, it is contradictory with it. (46)a 2 offers non-presuppositional controls. Finally, (46)b1-b2 are like (46)a1-a2, except that if $F, G$ is replaced with if not $G$, not $F$ - which makes it possible to test the predictions of the symmetric analysis We expected (46)a1A to be acceptable, (46)a1B and (46)a2B to be unacceptable, and - crucially - (46)b1A to have an intermediate status. The results are represented in (47) (see Schlenker 200b for further details, and Chemla and Schlenker (in progress) for a full discussion).

11 Aussi associates with focus, which can cause undesired ambiguities. To circumvent the problem, we inserted aussi right after a strong pronoun (e.g. eux aussi, literally 'them too'), which yielded unambiguous sentences. 
(47) Acceptability judgments for the canonical and reversed orders in conditionals

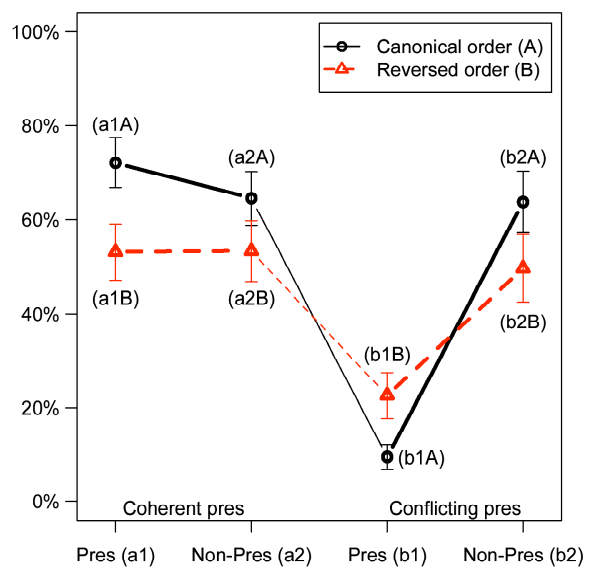

For conditionals, the results confirm the existence of a symmetric reading with an intermediate acceptability status; in a nutshell, the presence of a coherent trigger in the reversed order $(=(46) \mathrm{a} 1 \mathrm{~B})$ yields an acceptability rating which is lower than the analogous case in the canonical order $(=(46) \mathrm{a} 1 \mathrm{~A})$, but still much higher than the incoherent cases ((46)b1A and B). The experiment is still ongoing for a variety of other constructions, and additional triggers should be tested as well. Although the question should still be considered open, it can now be approached with experimental means.

\section{Open issues.}

\subsection{The Proviso Problem}

For sentences of the form ( $p$ and $q q$ ') or (if $p, q q$ '), all the 'new theories' predict a conditional presupposition if $p$, $q$. But as was argued in detail in van der Sandt 1992 and Geurts 1996, 1999, these predictions are often too weak, a difficulty that Geurts called the 'Proviso Problem' (see also Gazdar 1979, Karttunen and Peters 1979). The greatest difficulty is to explain the contrast between (48)a, which displays the expected presupposition, and (48)b, which typically yields a stronger (unconditional) presupposition.

(48)a. Peter knows that if the problem was easy / difficult, someone solved it.

(Geurts 1999)

$\neq>$ Someone solved the problem.

b. If the problem was easy / difficult, then it isn't John who solved it. (Geurts 1999)

$=>$ Someone solved the problem.

There is now a growing body of work that attempts to explain on pragmatic grounds why conditional presuppositions are sometimes strengthened (see for instance Beaver 2001, Heim 2006, Perez Caballo 2007, and van Rooij 2007). 
These solutions could be adapted to any of the new theories (Singh 2007 does explain it, but his account is in part syntactic).

\subsection{Restrictors}

Standard presupposition triggers that appear in relative clauses that restrict generalized quantifiers do not appear to yield universal inferences. This is to my a puzzle for all the theories we discussed (by contrast, DRT (van der Sandt 1992, Geurts 1999) and Beaver's version of dynamic semantics (Beaver 1994) make better predictions here). To illustrate the problem, consider (49):

(49) Among these 10 students...

a. nobody who applied is aware that he is incompetent.

$\Rightarrow>$ each of the students who applied is incompetent.

b. nobody who is aware that he is incompetent applied.

$\neq>$ each of the students is incompetent

$\neq>$ each of the students who applied is incompetent.

No clear universal inference is obtained in (49)b, whereas one is in (49)a. This pattern is confirmed when one considers the restrictor of other quantifiers, as is mentioned in Schlenker 2008a (Appendix B) and shown with experimental means in Chemla (to appear).

\subsection{Projection Patterns with Different Triggers}

Chemla's data show that presupposition projection from the nuclear scope depends on the precise semantics of the quantifier - which is an argument in favor of trivalent approaches (or of Chemla's own theory). However the significance of these facts is mitigated by the observation, developed in Charlow 2008, that universal inferences are regained when 'strong' triggers are used (for present purposes, we can take strong triggers to be ones that resist local accommodation). Furthermore, Charlow's findings extend to the restrictor position, where universal inferences can be regained too if the 'right' triggers are used. In both cases, he uses the trigger too associating with the verb smoke, in a context in which a salient alterantive is drink:

(50)a. None/some/(more than) two of these 10 students [ ${ }_{\mathrm{VP}} \operatorname{smoke}(\mathrm{s})_{\mathrm{F}}$ too]

$\Rightarrow>$ Each of these 10 students drinks.

b. Of these 10 students, (the) two who [vp smoke $_{\mathrm{F}}$ too] are blonde

$\Rightarrow$ Each of the 10 students drinks.

These data should of course be explored further in future research. As far as I can tell, the complex interaction we observe between the nature of the trigger and the semantics of the quantifier is a puzzle for all existing theories. 


\subsection{Linear vs. Structural Incrementalism}

All theories under consideration have an 'incremental' component that posits that certain principles must be satisfied as soon as a trigger is processed, going from left to right. In the theories we discussed, this incremental component literally considered the words as they appear from left to right. But as was suggested independently by E. Stabler and D. Fox and Ed Stabler, the algorithm should in the general case be applied to derivation trees rather than to strings. The simple language we have used in this discussion makes the two options equivalent, but only because it uses quite a few brackets to encode the derivational history of a sentence in the object language (see Fox 2008) ${ }^{12}$.

\subsection{Barker's Problem}

Chris Barker (p.c.) has noted that the simplest version of the incremental system of the Transparency theory (or of the theory of local contexts) will make disastrous predictions in (51):

(51) John awoke at 10am

Let us assume that the predicate awoke at $t$ presupposes had been sleeping up until $t$. Extended in the most natural way, the incremental theory would require in particular that for all modifiers $M$, for all predicative expressions $d$ ',

(52) $\mathrm{Cl}=(($ John (had slept and d') $) \mathrm{M}) \Leftrightarrow\left(\right.$ John $\left.\mathrm{d}^{\prime} \mathrm{M}\right)$

But now replace $M$ with at $8 a m$, at 9 am, at $10 a m$, at 11 am, at $12 \ldots$ Taking $d$ ' to be a tautological predicate, we can ensure that the right-hand side is true - with the effect that $\mathrm{C}$ should entail that John had been sleeping up until 8am, at 9, at 10, at 11, etc. - which is far too strong. The same problem arises in (53):

(53) John has stopped beating his dog.

The incremental theory (or rather a natural extension of it) predicts that for any Noun Phrase NP,

(54) $\mathrm{C} I=($ John $(($ used to beat and d') NP $)) \Leftrightarrow($ John d' NP $)$

By taking $d$ ' to be a tautological transitive verb, we will get an inference that John used to beat everything and everybody.

12 An alternative direction is to adopt the trivalent compositional approaches of Peters 1979, Beaver and Krahmer 2001 and George 2007, 2008. In these, linear order only plays a role within the domain of the arguments of a functor. 
A natural solution would be to apply the incremental theory only at points at which a presupposition trigger has been fed all its arguments (including adverbial ones). But the repercussions of such a move need to be carefully explored.

I conclude with a table summarizing in simplified form the predictions of the theories discussed here, as well as experimental or introspective data, with respect to three classes of phenomena: the existence of universal inferences, the availability of symmetric readings, and reaction times when presuppositions fail to be derived.

\begin{tabular}{|c|c|c|c|c|c|c|}
\hline & $\begin{array}{l}\text { (Every P.RR'), } \\
\text { (No P.RR') }\end{array}$ & $\begin{array}{l}\text { (>5 P.RR'), } \\
\text { (<5 P.R्RQ') }\end{array}$ & (=5 P.QQQ') & $\begin{array}{l}\left(Q^{\text {PP' }} \cdot \mathrm{R}\right), \\
\text { with Q a } \\
\text { quantifier }\end{array}$ & $\begin{array}{l}\text { Symmetric } \\
\text { Readings }\end{array}$ & $\begin{array}{l}\text { Reaction } \\
\text { times: } \\
\text { cancellation }\end{array}$ \\
\hline $\begin{array}{l}\text { Data (experiments): } \\
\text { 'Standard' } \\
\text { (Chiggerla) }\end{array}$ & Universal & $\begin{array}{l}\text { Non- } \\
\text { Universal }\end{array}$ & $\begin{array}{l}\text { Non- } \\
\text { Universal }\end{array}$ & $\begin{array}{l}\text { Non- } \\
\text { Universal }\end{array}$ & Disputed & costly \\
\hline $\begin{array}{l}\text { Data } \\
\text { (introspection): } \\
\text { 'Strong' triggers } \\
\text { (Charlow) }\end{array}$ & Universal & Universal & Universal & Universal & Disputed & $?$ \\
\hline $\begin{array}{l}\text { Dynamic } \\
\text { Semantics } \\
\text { Heim } 1983\end{array}$ & Universal & Universal & Universal & Universal & No & costly \\
\hline $\begin{array}{l}\text { Transparency } \\
\text { Theory } \\
\text { Schlenker } 2008 \\
\end{array}$ & Universal & $\begin{array}{l}\text { Almost } \\
\text { Universal }\end{array}$ & $\begin{array}{l}\text { Almost } \\
\text { Universal }\end{array}$ & $\begin{array}{l}\text { Almost } \\
\text { Universal }\end{array}$ & Yes, costly & not costly \\
\hline $\begin{array}{l}\text { Local Contexts } \\
\text { Schlenker } \\
\text { to appear }\end{array}$ & Universal & $\begin{array}{l}\text { Almost } \\
\text { Universal }\end{array}$ & $\begin{array}{l}\text { Almost } \\
\text { Universal }\end{array}$ & $\begin{array}{l}\text { Almost } \\
\text { Universal }\end{array}$ & Yes, costly & costly? \\
\hline $\begin{array}{l}\text { Trivalence } \\
\text { (differences between } \\
\text { several versions) }\end{array}$ & $\begin{array}{l}\text { Universal, but } \\
\text { not presup- } \\
\text { positional }\end{array}$ & $\begin{array}{l}\text { Non- } \\
\text { Universal }\end{array}$ & $\begin{array}{l}\text { Universal, } \\
\text { but not } \\
\text { presup- } \\
\text { positional } \\
\end{array}$ & $\begin{array}{l}\text { Depends on } \\
\text { the } \\
\text { quantifier }\end{array}$ & Yes, costly? & costly? \\
\hline $\begin{array}{l}\text { Constrained } \\
\text { Dynamic } \\
\text { Semantics } \\
\text { Rothschild, LaCasse }\end{array}$ & Universal & Universal & Universal & Universal & $\begin{array}{l}\text { Yes } \\
\text { (Rothschild)/ } \\
\text { No (LaCasse) }\end{array}$ & costly \\
\hline
\end{tabular}

\section{References}

Beaver, David: 1994, When Variables Don't Vary Enough. In M. Harvey and L. Santelmann (eds.), Semantics and Linguistic Theory 4, CLC Publications, Cornell.

Beaver, David: 2001, Presupposition and Assertion in Dynamic Semantics. CSLI, Stanford.

Beaver, David and Krahmer, Emiel: 2001, A partial account of presupposition projection. Journal of Logic, Language and Information 10.147-182. DOI 10.1023/A:1008371413822

Beaver, David: to appear, As brief as possible (but no briefer). To appear in Theoretical Linguistics. 
Beaver, David and Zeevat, Henk: 2007, Accommodation. In Ramchand, G. and C. Reiss (eds.), Oxford Handbook of Linguistic Interfaces, Oxford University Press.

Charlow, Simon: 2008, Strong "predicative" presuppositions. Ms. NYU.

Chemla, Emmanuel: 2007, Présuppositions et implicatures scalaires: études formelles et expérimentales, Doctoral dissertation, École des Hautes Études en Sciences Sociales, Paris.

Chemla, Emmanuel: 2008a, Similarity: Towards a unified account of scalar implicatures, free choice permission and presupposition projection. Under revision for Semantics and Pragmatics.

Chemla, Emmanuel: 2008b, Empirical Basis for a Theory of Presuppositions. Slides, UCL Colloquium, October 15, 2008.

Chemla, Emmanuel: 2008c, Transparency Theory: Empirical Issues and Psycholinguistic Routes. Theoretical Linguistics 34, 3: 229-236.

Chemla, Emmanuel: to appear a, Presuppositions of quantified sentences: Experimental Data. To appear in Natural Language Semantics.

Chemla, Emmanuel: to appear b, An Experimental Approach to Adverbial Modification. To appear in the proceedings of the Xprag 2007 conference in Berlin.

Davis, Steven (ed.): 1991, Pragmatics: A Reader, Oxford University Press.

Fox, Danny: to appear, Two Short Notes on Schlenker's Theory of Presupposition Projection. To appear in Theoretical Linguistics.

George, Benjamin: 2008a, Predicting Presupposition Projection: Some alternatives in the strong Kleene tradition. Manuscript, UCLA. Available on Semantics Archive at http://semanticsarchive.net/Archive/DYOYTgxN/

George, Benjamin: 2008b, Presupposition Repairs: A Static, Trivalent Approach to Predicting Presupposition. MA thesis, UCLA. Available on Semantics Archive at http://semanticsarchive.net/Archive/2ZiYmEyN/

Geurts, Bart: 1999, Presupposition and Pronouns. Elsevier.

Heim, Irene: 1983, On the Projection Problem for Presuppositions. In D. Flickinger et al. (eds), Proceedings of the Second West Coast Conference on Formal Linguistics, 114-125. Reprinted in Davis 1991.

Heim, Irene: 1990, Presupposition Projection. In R. van der Sandt (ed.), Reader for the Nijmegen Workshop on Presupposition, Lexical Meaning, and Discourse Processes. University of Nijmegen.

Heim, Irene: 1992, Presupposition projection and the semantics of attitude verbs. Journal of Semantics, 9(3), 183-221. DOI 10.1093/jos/9.3.183

Karttunen, Lauri: 1974, Presupposition and Linguistic Context. Theoretical Linguistics 1: 181-194. Reprinted in Davis 1991.

Krahmer, Emiel: 1998, Presupposition and Anaphora. CSLI Publications.

Krahmer, Emiel: to appear, Why Be Articulate? (Two ways to look at the Transparency theory). To appear in Theoretical Linguistics. 
Krifka, Manfred: 2001, For a Structured Meaning Account of Questions and Answers. In C. Féry \& W. Sternefeld (eds.), Audiatur Vox Sapientia. A Festschrift for Arnim von Stechow, Akademie Verlag (= studia grammatica 52), Berlin, 287-319.

LaCasse, Nicolas: 2008, Constraints on Connectives and Quantifiers: Solving the over-generation problem of dynamic semantics. MA thesis, UCLA.

Peters, Stanley: 1979, A truth-conditional formulation of Karttunen's account of presupposition. Synthese, 40:301-316.

Rothschild, Daniel: 2008a, Presupposition Projection in Dynamic Semantics. Manuscript, Columbia University.

Rothschild, Daniel: 2008b, Transparency Theory and its Dynamic Alternatives. Theoretical Linguistics 34, 3: 261-268.

Rothschild, Daniel: to appear, Presupposition Projection and Logical Equivalence. To appear in Philosophical Perspectives.

Schlenker, Philippe: 2007, Anti-Dynamics: Presupposition Projection Without Dynamic Semantics. Journal of Logic, Language and Information 16, 3: 325-256. DOI 10.1007/s10849-006-9034-X

Schlenker, Philippe: 2008a, Be Articulate: A Pragmatic Theory of Presupposition Projection. To appear as a target article (with commentaries) in Theoretical Linguistics.

Schlenker, Philippe: 2008b, Presupposition Projection: Explanatory Strategies. To appear in Theoretical Linguistics.

Schlenker, Philippe: 2009, Presuppositions and Local Contexts. Manuscript, Institut Jean-Nicod and NYU.

Schlenker, Philippe: to appear, Local Contexts. To appear in Semantics \& Pragmatics.

Soames, Scott: 1989, Presupposition. In D. Gabbay and F. Guenthner (eds), Handbook of Philosophical Logic IV, 553-616.

Stalnaker, Robert: 1974, Pragmatic Presuppositions. In Munitz, M. and Unger, P. (eds.) Semantics and Philosophy. New York: New York University Press. Reprinted in Davis 1991.

Stalnaker, Robert: 1978, Assertion. In Cole, P. (ed.) Syntax and Semantics, vol. 9: Pragmatics: 315-322. Reprinted in Davis 1991.

Thomason, Richard, Stone, Matthew, and DeVault, David: 2006, Enlightened Update: A Computational Architecture for Presupposition and Other Pragmatic Phenomena. Manuscript, available online at http://www.pragmatics.osu.edu/links/events/enlightened-update.pdf

Unger, Christina and van Eijck, Jan: 2007, The Epistemics of Presupposition Projection. Abstract, Amsterdam Colloquium 2007.

van der Sandt, Rob: 1992, Presupposition Projection as Anaphora Resolution. Journal of Semantics 9(4): 333-377. DOI 10.1093/jos/9.4.333

van Rooij, Robert: 2007, Strengthening Conditional Presuppositions. Journal of Semantics, 2007, 24: 289-304. DOI 10.1093/jos/ffm007 